\title{
The Adhesion-GPCR BAI1 Promotes Excitatory Synaptogenesis by Coordinating Bidirectional Trans-synaptic Signaling
}

\author{
다en-Kuei Tu, ${ }^{1,2}$ Joseph G. Duman, ${ }^{1}$ and Kimberley F. Tolias ${ }^{1,2,3}$ \\ ${ }^{1}$ Department of Neuroscience, ${ }^{2}$ Graduate Program in Integrative Molecular and Biomedical Sciences, and ${ }^{3}$ Verna and Marrs McLean Department of \\ Biochemistry and Molecular Biology, Baylor College of Medicine, Houston, Texas 77030
}

Excitatory synapses are specialized cell-cell contacts located on actin-rich dendritic spines that mediate information flow and storage in the brain. The postsynaptic adhesion-G protein-coupled receptor (A-GPCR) BAI1 is a critical regulator of excitatory synaptogenesis, which functions in part by recruiting the Par3-Tiam1 polarity complex to spines, inducing local Rac1 GTPase activation and actin cytoskeletal remodeling. However, a detailed mechanistic understanding of how BAI1 controls synapse and spine development remains elusive. Here, we confirm that BAI1 is required in vivo for hippocampal spine development, and we identify three distinct signaling mechanisms mediating BAIl's prosynaptogenic functions. Using in utero electroporation to sparsely knock down BAIl expression in hippocampal pyramidal neurons, we show that BAIl cell-autonomously promotes spinogenesis in the developing mouse brain. BAI1 appears to function as a receptor at synapses, as its extracellular $\mathrm{N}$-terminal segment is required for both its prospinogenic and prosynaptogenic functions. Moreover, BAIl activation with a Stachel-derived peptide, which mimics a tethered agonist motif found in A-GPCRs, drives synaptic Racl activation and subsequent spine and synapse development. We also reveal, for the first time, a trans-synaptic function for BAIl, demonstrating in a mixed-culture assay that BAIl induces the clustering of presynaptic vesicular glutamate transporter 1 (vGluT1) in contacting axons, indicative of presynaptic differentiation. Finally, we show that BAI1 forms a receptor complex with the synaptogenic cell-adhesion molecule Neuroligin-1 (NRLN1) and mediates NRLN1-dependent spine growth and synapse development. Together, these findings establish BAI1 as an essential postsynaptic A-GPCR that regulates excitatory synaptogenesis by coordinating bidirectional trans-synaptic signaling in cooperation with NRLN1.

Key words: adhesion GPCR; BAI1; dendritic spines; Neuroligin; Rac1; synaptogenesis

Significance Statement

Adhesion-G protein-coupled receptors are cell-adhesion receptors with important roles in nervous system development, function, and neuropsychiatric disorders. The postsynaptic adhesion-G protein-coupled receptor BAIl is a critical regulator of dendritic spine and excitatory synapse development. However, the mechanism by which BAIl controls these functions remains unclear. Our study identifies three distinct signaling paradigms for BAI1, demonstrating that it mediates forward, reverse, and lateral signaling in spines. Activation of BAIl by a Stachel-dependent mechanism induces local Racl activation and subsequent spinogenesis/ synaptogenesis. BAIl also signals trans-synaptically to promote presynaptic differentiation. Furthermore, BAIl interacts with the postsynaptic cell-adhesion molecule Neuroligin-1 (NRLN1) and facilitates NRLN1-dependent spine growth and excitatory synaptogenesis. Thus, our findings establish BAIl as a functional synaptogenic receptor that promotes presynaptic and postsynaptic development in cooperation with synaptic organizer NRLN1.

\section{Introduction}

Synapses are specialized cell-cell contacts that mediate information flow and storage in the brain. The postsynaptic loci of most

Received Dec. 6, 2017; revised June 13, 2018; accepted July 5, 2018.

Author contributions:Y.-K.T., J.G.D., and K.F.T. designed research; Y.-K.T. and J.G.D. performed research; Y.-K.T. and J.G.D. contributed unpublished reagents/analytic tools; Y.-K.T. and J.G.D. analyzed data; Y.-K.T., J.G.D., and K.F.T. wrote the paper. excitatory synapses in the mammalian brain are small actin-rich dendritic protrusions called spines (Tada and Sheng, 2006). Den-

This work was supported by National Institutes of Health Grants R01MH109511 and R01NS062829 to K.F.T. and Grant K01MH086119 to J.G.D. We thank the Allen Brain Atlas for images; Matthew Rasband and Tammy Szu-Yu Ho for sharing reagents and expertise; Karen Firozi for technical and administrative support; Shalaka Mulherkar for technical support; Takashi Tokino for providing the BAI1 construct; Erwin Van Meir for providing Vstat; Peter Scheiffele for providing PCAG-NL1B and PCAG-NRXN1B-AS4(-); and Michiyuki Matsuda for providing RaichuEV-Rac1. 
dritic spines rapidly remodel during development and activitydependent synaptic plasticity associated with learning and memory, and their number and morphology reflect synaptic number and strength. Notably, spine and synapse abnormalities are a common feature of neuropsychiatric disorders, including intellectual disabilities, autism spectrum disorders (ASDs), schizophrenia, and Alzheimer's disease (Kulkarni and Firestein, 2012). Thus, elucidating the mechanisms that regulate the formation, plasticity, and maintenance of spines and synapses is crucial for our knowledge of normal brain function and disease.

Brain-specific angiogenesis inhibitor 1 (BAI1/ADGRB1) is an adhesion-G protein coupled receptor (A-GPCR) that we previously identified as a critical regulator of spine and synapse development (Duman et al., 2013). Like most A-GPCRs, BAI1 has an extended extracellular N-terminal segment (NTS) containing multiple adhesion domains, including five thrombospondin Type 1 repeats (TSRs) and a GAIN domain located just $\mathrm{N}$-terminal to a seven-transmembrane serpentine motif found in all GPCRs (Duman et al., 2016). Highly enriched at the postsynaptic density (PSD), BAI1 is required for both spinogenesis and excitatory synaptogenesis in hippocampal and cortical neurons (Duman et al., 2013; Zhu et al., 2015). BAI1 regulates these processes in part by recruiting the Rac1-guanine nucleotide exchange factor Tiam 1 and the polarity protein Par3 to spines, where Tiam 1 mediates localized Racl GTPase activation (Duman et al., 2013). Activated Racl, in turn, drives actin cytoskeleton remodeling, promoting spine and synapse growth (Govek et al., 2005). BAI1 also stabilizes the major synaptic scaffolding protein PSD-95 by binding to the E3 ubiquitin ligase MDM2 and preventing it from targeting PSD-95 for degradation (Zhu et al., 2015). Genetic ablation of BAI1 results in mice with severe deficits in hippocampusdependent spatial learning and memory, enhanced LTP, and impaired LTD (Zhu et al., 2015).

Despite these recent advances, many unanswered questions remain about the functions of synaptic BAIl. For instance, it is not clear whether BAI1 coordinates presynaptic and postsynaptic differentiation or whether it purely acts cell-autonomously in the postsynaptic neuron. Furthermore, although BAIl is an A-GPCR, it is unknown whether BAIl functions as a receptor in the nervous system. BAI1 has no known synaptic ligands, and no published evidence to date indicates that BAI1 relies on ligand binding for its prospinogenic or prosynaptogenic activity. Likewise, neither Tiam1/Par3 targeting nor PSD-95 stabilization has been demonstrated to be actively regulated through BAI1-mediated signal transduction. However, precedent suggests that BAI1 is likely capable of inducing ligand-dependent signaling at synapses, as BAIl functions in the immune system as a phosphatidylserine receptor that triggers the engulfment of apoptotic cells by macrophages (Park et al., 2007). Moreover, the closely related A-GPCR BAI3 mediates ligand-dependent excitatory synaptogenesis in the cerebellum. BAI3 localizes to cerebellar Purkinje cell spines and regulates Purkinje cell innervation by both parallel and climbing fibers (Kakegawa et al., 2015; Sigoillot et al., 2015). Climbing fiber expression of the secreted C1q-like complement factor C1ql1 and its subsequent interaction with BAI3 are required for the proper formation, refinement, and maintenance of climbing fiber-Purkinje cell excitatory synapses. Although BAI1

The authors declare no competing financial interests.

Correspondence should be addressed to Dr. Kimberley F. Tolias, Baylor College of Medicine, One Baylor Plaza, Room S607, Mailstop BCM295, Houston, TX 77030. E-mail: tolias@bcm.edu.

DOI:10.1523/JNEUROSCI.3461-17.2018

Copyright $\odot 2018$ the authors $\quad 0270-6474 / 18 / 388389-19 \$ 15.00 / 0$ and BAI3 share most of their $\mathrm{N}$-terminal extracellular signaling domains, the BAI3-C1ql1 interaction is mediated by BAI3's CUB domain, which is not present in BAIl (Duman et al., 2016). Thus, the function of BAI1's extracellular signaling domains in synaptogenesis remains elusive.

Understanding BAIl's function in the nervous system is important because of its implications for neural circuit development and neurological disease. The human BAI1 gene ADGRB1 is located in a hot spot for de novo germline mutations in patients with ASD (Michaelson et al., 2012). Furthermore, BAI1 expression is upregulated in mouse models of Rett and MeCP2 duplication syndromes (Chahrour et al., 2008) and downregulated in glioblastoma, where BAI1 expression is inversely correlated with neovascularization (Cork and Van Meir, 2011). Because GPCRs are some of the most successful therapeutic targets for disease intervention, further insight into BAIl regulation and function could facilitate the development of new treatments for the aforementioned disorders.

Here, we confirm that BAIl is essential in the mouse brain for hippocampal dendritic spinogenesis, and we demonstrate that the extracellular NTS of BAI1 is required for its pro-spinogenic/ synaptogenic function. At synapses, we show that BAIl functions as a receptor, inducing Rac1 activation and subsequent spine and excitatory synapse development via a novel Stachel signaling mechanism unique to A-GPCRs. We also identify a trans-synaptic function for BAIl, demonstrating that it can signal in reverse to promote presynaptic differentiation. Finally, we show that, at the PSD, BAI1 interacts with the synaptogenic cell-adhesion molecule Neuroligin-1 (NRLN1) and facilitates NRLN1-dependent spine and synapse growth. Thus, BAIl is a functional synaptogenic receptor that promotes both presynaptic and postsynaptic development in cooperation with the synaptic organizer NRLN1. These results offer a greatly expanded view of the signaling mechanisms by which BAI1 mediates spinogenesis and excitatory synaptogenesis.

\section{Materials and Methods}

Antibodies. Mouse monoclonal antibodies against the following proteins were used: Flag (1:1000, M2 Sigma-Aldrich), HA (1:300 immunoprecipitation, 1:1000 immunofluorescent staining [IF]), Western blotting [WB], 16B12, BioLegend), c-myc (1:1000 IF, WB, 9E10, Santa Cruz Biotechnology), PSD-95 (1:500 IF, MA1-046, Fisher Thermo Scientific), NRLN1 (1:1000 WB, 4C12, Synaptic Systems), and N-cadherin (1:1000 IF, 610920, BD Bioscience). We also used rabbit polyclonal antibodies against BAI1 (1:1000 IF, WB, antibody generated against the $\mathrm{C}$ terminus of BAI1, amino acids 1180-1584) (Duman et al., 2013) and vGluT1 (1:1000 IF, 135-303, Synaptic Systems). Secondary antibodies used include goat polyclonal antibodies labeled with HRP for WB or with Cy3, Cy5, or AlexaFluor-647 for IF (Jackson ImmunoResearch Laboratories).

DNA reagents. The following expression constructs were generous gifts: human BAI1 in pcDNA3.1(+) (Dr. Tokino, Sapporo Medical University), Vstat in pcDNA3.1(+) (Dr. Van Meir, Emory University) (Kaur et al., 2005), NRLN1B (pCAG-NL1B), and Neurexin1B (pCAGNRXN1B-AS4(-)) (Dr. Scheiffele, University of Basel) (Addgene plasmids \#15261, \#58267), and RaichuEV-Racl (Dr. Matsuda, Kyoto University) (Komatsu et al., 2011). The BAI1 deletion mutant (B1 $\Delta \mathrm{N}$, lacking amino acids 125-880) was generated by PCR cloning and Gibson assembly (Gibson et al., 2009). The pSuper-shRNA construct against BAI1 (5'-CCCGGACCCTCGTCGTTAC-3') was described previously (Duman et al., 2013). This hairpin successfully knocks down rodent forms of BAIl but does not affect human BAIl, allowing for knock down $(\mathrm{Kd})$-rescue experiments. A pSuper-shRNA construct against NRLN1 (5'-GGAAGGTACTGGAAATCTA-3') was designed based on a shRNA sequence reported by Chih et al. (2005). All constructs used were sequence verified.

Cell culture and transfections. Dissociated hippocampal neurons were prepared from embryonic (E)19 Long-Evans rats of either sex and cul- 
tured in 24-well plates at a density of 100,000-120,000 cells/well, as described previously (Tolias et al., 2005; Duman et al., 2013). Each well contained a single nitric acid-washed glass coverslip coated with 20 $\mu \mathrm{g} / \mathrm{ml}$ poly-D-lysine and $3 \mu \mathrm{g} / \mathrm{ml}$ laminin. Neurons were grown in Neurobasal medium (Invitrogen) supplemented with B27 (Invitrogen), $2 \mathrm{~mm}$ glutamine, and $100 \mathrm{U} / \mathrm{ml}$ penicillin/streptomycin. For HEK293T cells, media consisted of DMEM supplemented with $10 \%$ FBS and $100 \mathrm{U} / \mathrm{ml}$ penicillin/streptomycin. For COS7 cells, media contained DMEM supplemented with HyClone FetalClone-3 (GE Healthcare, SH30109), 2 mM glutamine, and $100 \mathrm{U} / \mathrm{ml}$ penicillin/streptomycin. Both HEK293T cells and COS7 cells were cultured on poly-D-lysine-coated glass coverslips for immunostaining. For transfections, 6-8 days in vitro (DIV) hippocampal neurons and HEK293T cells were transfected using a calcium phosphate method, as previously described (Tolias et al., 2005; Duman et al., 2013). COS7 cells used in the mixed-culture assays were transfected using Lipofectamine 2000 (Invitrogen).

Biochemistry. Cells were lysed in NP40 lysis buffer (50 mm Tris, $\mathrm{pH} 7.5$, $150 \mathrm{~mm} \mathrm{NaCl}, 1 \% \mathrm{NP}-40,1 \mathrm{~mm}$ EDTA, pH 8.0, 5\% glycerol) with $1 \mathrm{~mm}$ DTT, Complete protease inhibitor mixture (Roche), $10 \mathrm{~mm} \mathrm{NaF}, 1 \mathrm{~mm}$ $\mathrm{NaVO}_{3}$, and $10 \mathrm{~mm} \beta$-glycerophosphate. For coimmunoprecipitation, HEK293T cells were transfected with cDNA expression vectors for proteins of interest. Cells were lysed using NP40 lysis buffer $48 \mathrm{~h}$ after transfection, and then cleared lysate was incubated with antibodies for $2 \mathrm{~h}$ at $4^{\circ} \mathrm{C}$. Following incubation, protein $\mathrm{G}$ beads (Pierce) were added and incubated at $4^{\circ} \mathrm{C}$ for another $2 \mathrm{~h}$. Beads were spun down and washed twice with RIPA buffer (50 mm Tris, pH 7.5, $150 \mathrm{~mm} \mathrm{NaCl,} 1 \% \mathrm{NP}-40$, $0.5 \%$ DOC, $0.1 \%$ SDS, 1 mM EDTA), and then immunoprecipitated proteins were subjected to SDS-PAGE, transferred to Immobilon-P (Millipore) PVDF membranes, and analyzed by WB using standard techniques. All WBs were visualized on an ImageQuant LAS4000 (GE Lifesciences) or a Li-Cor Odyssey Fc.

Immunocytochemistry and microscopy. Cell cultures were fixed with $4 \%$ PFA/sucrose solution and washed with PBS. Antibodies against PSD-95 were applied in PBS containing $0.24 \%$ gelatin and $0.72 \%$ Triton X-100. All other antibodies were applied in PBS containing 5\% goat serum, 2\% BSA, and $0.1 \%$ Triton X-100. Postfixation and staining, cells were mounted using the aqueous mounting solution FluorSave (EMD Millipore 345789). Confocal images for Figures 1-5, and 8 were collected on a Zeiss LM 780 confocal microscope with a $63 \times$ oil-immersion objective. For all cultured neuron experiments, $0.4-0.45 \mu \mathrm{m}$ intervals were used for $z$ stacks. For tissue culture cells, single confocal images were collected where cells contact the glass coverslips. Confocal images for Figure 6 were collected on a Leica TCS SP2 confocal microscope with a $63 \times$ oilimmersion objective. $z$-stack intervals were taken $0.2 \mu \mathrm{m}$ between images. All microscopy images were blinded before collection and were not unblinded until analysis was complete. After setting image collection gain levels from control slide before blinding, all images were collected with only EGFP visible to the experimenter. Images collected before blinding were discarded and not included in analysis. In rescue and overexpression experiments (see Figs. 2, 3, 9), neurons that did not match predefined expression levels (e.g., rescue construct did not express or expressed too much, overexpression levels were too low or too high) were collected due to blinding but were then excluded from the data pool. Unless otherwise noted, all cells were transfected with EGFP to fill and mark cells that had been successfully transfected. For images with multiple channels, EGFP signal was used as a mask to exclude staining from nontransfected cells.

In utero electroporation and in vivo experiments. In utero electroporation was performed according to protocols described previously (Hedstrom et al., 2007). pSuper (control) vector or pSuper-shRNA plasmids were injected along with pCx-EGFP into E14 ICR mouse embryos of either sex (Charles River). Pups were born and then euthanized at postnatal day $(\mathrm{P}) 21$. Their brains were dissected and fixed at $4^{\circ} \mathrm{C}$ with $4 \% \mathrm{PFA}$ for $1 \mathrm{~h}$ on ice, and then equilibrated in ice-cold $20 \%$ sucrose (w/v). For staining, $30 \mu \mathrm{m}$ coronal sections were sectioned on a cryotome (Thermo Fisher Scientific CryoStar NX70). Sections were stained in PBS with $0.3 \%$ Triton X-100 and 5\% BSA for 2-3 d with BAI1 antibodies and then mouse-anti-rabbit secondary antibodies for $1 \mathrm{~d}$. Sections were imaged using a confocal microscope as above (Carl Zeiss), with $0.10-0.12 \mu \mathrm{m}$ between $z$-sections.

Mixed-culture assays. Mixed-culture assays were performed as described previously (Biederer and Scheiffele, 2007). Dissociated hippocampal cultures were prepared as noted above. COS7 cells were transfected with EGFP and either N-cadherin (negative control), NRLN1 (positive control), BAI1, or B1 $\Delta \mathrm{N}$. One day after transfection, the COS7 cells were trypsinized and seeded at a density of $30 \times 10^{3}$ cells/well onto 5 or 9 DIV hippocampal cultures for analysis at 6 or 10 DIV, respectively. Cells were fixed in $4 \%$ PFA and stained with anti-vGluT1 antibodies to mark presynaptic clusters and anti-Tau 1 antibodies to mark axons. Mean intensity and size of individual v-Glutl puncta overlapping EGFPmarked cells were also analyzed for each experimental condition as a control for comparing puncta across different conditions. Additional experiments were performed to verify surface expression of proteins of interest.

Cell-cell trans-adhesion assay. Cell-cell adhesion assays were performed as described previously (Woo et al., 2009). COS7 cells were transfected with either EGFP or mRuby2 in combination with NRLN1, Neurexin-1 $\beta$ (NRXN1), or BAI1. After 48 h, cells were trypsinized. The trypsin was inactivated using DMEM containing Fetal Clone III (GE Healthcare) and spun down at $1000 \mathrm{rpm}$ for $5 \mathrm{~min}$. Cells were resuspended in serum-free DMEM buffered using 0.1 M HEPES, pH 7.0, and allowed to recover while rotating at room temperature for $1 \mathrm{~h}$. After the incubation, equal volumes of cells expressing different surface proteins of interest were mixed in different combinations and allowed to rotate at room temperature for $30 \mathrm{~min}$. The mixed cell solutions were transferred to individual wells of a 24-well tissue culture plate (Corning Costar 3524). $z$-stacked images were taken at $10 \times$ on an Axio Observer.Z1 (Carl Zeiss), and cell aggregates were quantified from single $z$-stack frames as being groups of four or more clustered cells that contained at least one red and one green cell.

BAI1 Stachel peptide experiments. The Stachel peptide for BAI1 was designed according to Liebscher et al. (2014), using a peptide sequence similar to that used previously (Kishore et al., 2016). The active BAI1 Stachel peptide (STFAILAQLSADANMEKAT) and the scramble control peptide (ATLAMDSATNAIQSAELFK) were synthesized by Biomatik. Hippocampal neurons in 24-well plates were treated with 600 $\mu \mathrm{M}$ active or scrambled Stachel peptides in $37^{\circ} \mathrm{C}$ prewarmed $1.5 \times$ ACSF (119 m M NaCl, 26.2 mm NaHCO, $2.5 \mathrm{~mm} \mathrm{KCl,} 1 \mathrm{~mm} \mathrm{NaH}_{2} \mathrm{PO}_{4}$, $1.3 \mathrm{~mm} \mathrm{MgCl}_{2}$, and $10 \mathrm{~mm}$ glucose) for $1 \mathrm{~h}$ before fixation for IF or lysis for immunoprecipitation.

Live imaging of neurons and Förster-resonance energy transfer (FRET). To measure Racl activation in live neurons in response to the Stachel peptide, 6 DIV dissociated rat hippocampal neurons were transfected with YFP, the RaichuEV-Racl probe, and either empty pSuper vector or shRNA against BAI1. At 13-14 DIV, neurons were transitioned from cultured media to ACSF. Neurons expressing low to moderate levels of RaichuEV-Racl were imaged using an epifluorescent microscope (Carl Zeiss) at $37^{\circ} \mathrm{C}$ to establish baseline levels before peptide treatment. FRET images were collected using the following settings: FRET, excitation 458 $\mathrm{nm}$, emission 530-600 nm; CFP, excitation $458 \mathrm{~nm}$, emission 470-500 $\mathrm{nm}$; YFP, excitation $514 \mathrm{~nm}$, emission 530-500 nm. Neurons were then treated with $600 \mu \mathrm{M}$ active or scrambled BAIl Stachel peptide in ACSF for $1 \mathrm{~h}$ as described above. The same neurons were then imaged using the epifluorescent microscope (Carl Zeiss) to collect final values after treatment. Cross-sectional surface area of spines was also analyzed for each time point for each neuron.

Data analysis. All measurements of spines in 3D confocal $z$-stack images were analyzed using Imaris (Bitplane Scientific). EGFP-expressing neurons were used for all analyses. Spines were modeled by the AutoPath tracing function in Imaris for all parameters. Spine and synapse data were collected in a blinded fashion from only secondary or tertiary segments of dendrites ( $>100 \mu \mathrm{m}$ per neuron). The colocalization plugin with the Pearson colocalization coefficient was used to analyze all overlap between fluorescent signals. Excitatory synapses were analyzed using the colocalization plugin of Imaris assessing the overlap between the vGluT1 (presynaptic marker) and the PSD-95 (postsynaptic marker) signals. Resultant colocalized puncta were quantified using the Spots function in 
A
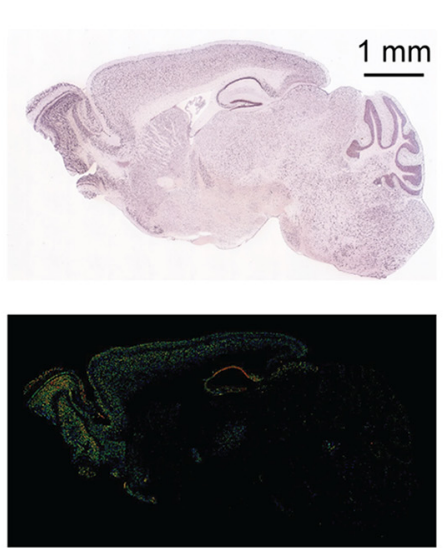

B

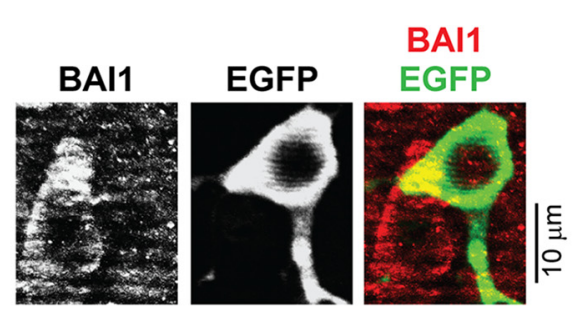

C
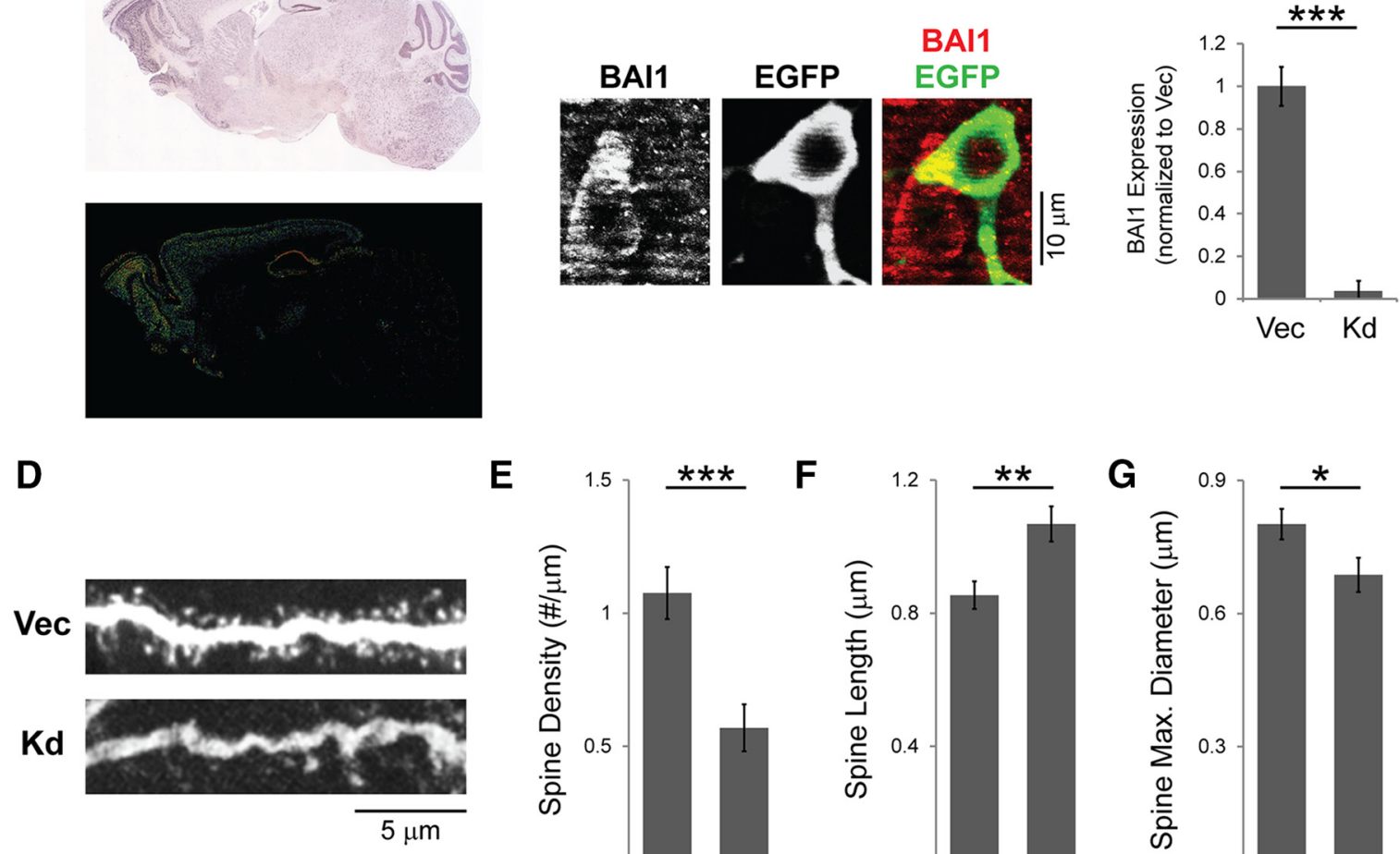

$\mathbf{E}$
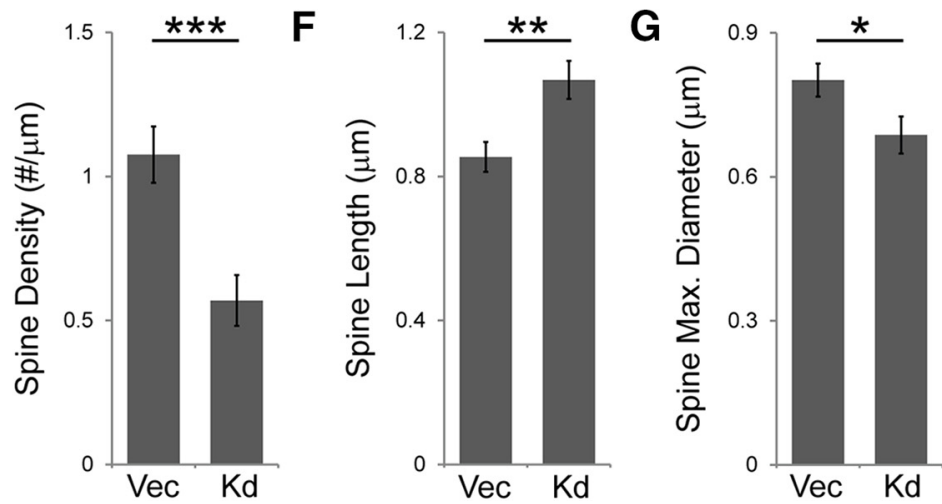

Figure 1. BAl1 is required in vivo for proper hippocampal pyramidal neuron spinogenesis. $A$, Top, Representative in situ hybridization image showing expression of BAI1 mRNA in a sagittal section of an adult mouse brain. Bottom, Intensity-coded summary image displaying low (blue) to high (red) BAl1 expression. Expression of BAl1 is high in the hippocampus and throughout the cortex. Images courtesy of the Allen Brain Atlas. Scale bar, $1 \mathrm{~mm}$. B, Representative images of hippocampal pyramidal neurons from a P21 mouse that underwent in utero electroporation of a BAl1-directed shRNA and EGFP on E14. At P21, transfected pyramidal neurons (green) show a lack of BAl1 staining (red) relative to neighboring untransfected neurons. Scale bar, $10 \mu \mathrm{m}$. C, Quantification of BAI1 knock down (Kd) using fluorescence intensity. BAI1 staining is dramatically reduced in EGFP-positive neurons expressing BAI1 shRNAs (Kd) compared with untransfected neighboring neurons (Vec) ( $p=0.00013$, unpaired $t$ test). D, Representative images of secondary dendrites from hippocampal pyramidal neurons near the border between $C A 1$ and the subiculum from mice treated as in $\boldsymbol{A}$, expressing EGFP with empty vector (Vec) or shRNA against BAI1 (Kd). Scale bar, $5 \mu \mathrm{m}$. $\boldsymbol{E}-\mathbf{G}$, Quantification of spine density $(\boldsymbol{E})$, spine length $(\boldsymbol{F})$, and spine maximum diameter ( $\boldsymbol{G})$. BAl1 Kd reduced spine density by $50 \%$ ( $p=0.00026$, unpaired $t$ test), increased spine length ( $p=0.00235$, unpaired $t$ test), and decreased spine head size ( $p=0.03029$, unpaired $t$ test). All imaging and quantification were performed blinded to condition. $N=3-5$ mice; $n=19$ or 20 neurons per condition. Data are mean \pm SEM. ${ }^{*} p<0.05,{ }^{* *} p<0.01,{ }^{* * *} p<0.001$.

Imaris. To enhance visualization and quantification of synapses on EGFP-expressing transfected neurons, we used the EGFP signal to mask vGluT1 and PSD-95 signals from nontransfected neurons. Signal intensity in each biological replicate was held consistent for quantification of excitatory synapse puncta. Pixel-by-pixel FRET was calculated using PixFRET (Feige et al., 2005) from National Institutes of Health ImageJ. We corrected the FRET and donor images for spectral crossover and direct excitation of the acceptor and then did pixel-by-pixel ratios of the acceptor emission to the donor emission. This corrects for differences in probe expression between different neurons.

Statistical tests and experimental design. All sample sizes and experimental design were based on previous published data from our laboratory, similar experiments, and standards in the field. All imaging and quantitative analyses were performed double-blinded. All data were plotted using Microsoft Excel, and data indicated on all graphs are mean \pm SEM. All statistical analyses were performed using Microsoft Excel (unpaired Student's $t$ test between two factors), Minitab 18.1 or Kaleidagraph 4.5 (one-way and two-way ANOVAs with Tukey Correction for multiple pairwise comparisons). The threshold for statistical significance was defined using $p$ values at $95 \%$ two-tailed confidence $(p<0.05)$.

\section{Pairwise comparison statistics}

Pairwise $t$ test $t$ values for Figure $6 \mathrm{H}$ were as follows: N-cad-Vec: $t=$ $-1.13, p=0.789$; B1-Vec: $t=3.26, p=0.021$; B1 $\Delta \mathrm{N}-\mathrm{Vec}: t=0.15, p=$ 1.000; N1-Vec: $t=9.89, p=0.000$; B1-N-cad: $t=3.44, p=0.013$; B1 $\Delta \mathrm{N}-\mathrm{N}$-cad: $t=1.20, p=0.751 ; \mathrm{N} 1-\mathrm{N}$-cad: $t=8.12, p=0.000$;
B1AN-B1: $t=-2.90, p=0.049$; N1-B1: $t=6.63, p=0.000$; N1-B1AN: $t=9.10, p=0.000$. Individual confidence level $=99.32 \%$.

Pairwise $t$ test $t$ values for Figure 6I were as follows: N-cad-Vec: $t=$ $-0.01, p=1.000$; B1-Vec: $t=3.99, p=0.001$; B1 $\Delta \mathrm{N}-\mathrm{Vec}: t=-0.20$, $p=1.000$; N1-Vec: $t=7.69, p=0.000$; B1-N-cad: $t=3.08, p=0.024$; B1 $\Delta \mathrm{N}-\mathrm{N}$-cad: $t=-0.17, p=1.000$; N1-N-cad: $t=5.90, p=0.000$; B1AN-B1: $t=-3.88, p=0.002$; N1-B1: $t=3.59, p=0.005$; N1-B1AN: $t=7.28, p=0.000$. Individual confidence level $=99.35 \%$.

\section{Results}

BAI1 functions in vivo in a cell-autonomous manner to promote spinogenesis in hippocampal pyramidal neurons BAI1 is a PSD-enriched A-GPCR that has recently emerged as a critical regulator of spine and excitatory synapse development (Duman et al., 2013; Zhu et al., 2015). In situ hybridization data suggest that BAI1 is highly expressed in the mouse brain throughout the cortex and hippocampus (Fig. 1A). To determine whether BAI1 functions cell-autonomously to promote spinogenesis in the hippocampus, we sparsely knocked down BAI1 expression in vivo by introducing a BAI1-directed shRNA (Duman et al., 2013) and EGFP into the forebrain of embryonic day (E)14 mouse embryos using in utero electroporation. EGFP not only marks the transfected neurons, but also enables visualization of their morphology. Evaluation of postnatal day (P)21 mice revealed clear 
EGFP expression in hippocampal pyramidal neurons near the border between CA1 and the dorsal subiculum. BAIl knock down $(\mathrm{Kd})$ was confirmed in these mice through immunohistochemistry, where a significant reduction in BAI1 levels was observed in EGFP-positive hippocampal pyramidal neurons expressing BAI1 shRNAs compared with adjacent untransfected neurons (Fig. 1 B, C; Control: $1.000 \pm 0.091$; BAI1 Kd: $0.038 \pm$ $0.046 ; p=0.00013$, unpaired $t$ test $N=3-5 ; n=19$ or 20 ). Sparse BAI1 Kd decreased spine density in hippocampal pyramidal neurons by $50 \%$ (Fig. $1 D, E ; p=0.00026, t=3.9575$ ), increased spine length (Fig. $1 D, F ; p=0.00235, t=3.2730$ ), and reduced spine head size (Fig. $1 D, G ; p=0.03029, t=2.2580$ ), all relative to EGFP-positive neurons expressing an shRNA control vector. A comparable decrease in spine density was observed when only basal dendrites were considered (Control: $1.074 \pm 0.146$; BAI1 Kd: $0.549 \pm 0.109 ; p=0.0051$, unpaired $t$ test). These spine alterations are similar in type and magnitude to those caused by sparse BAI1 Kd both in vivo in pyramidal neurons of the cingulate and somatosensory cortices and in vitro in cultured hippocampal neurons (Duman et al., 2013), suggesting that BAI1 promotes spine development in the hippocampus in a cell-autonomous manner.

\section{The prospinogenic and prosynaptogenic functions of BAI1 require its extracellular NTS}

Like all A-GPCRs, BAI1 possesses a long extracellular NTS with a variety of adhesion domains and motifs, including an RGD motif (RGD), five TSRs, a hormone binding domain, and a GAIN domain typical of A-GPCRs (Duman et al., 2016) (Figure 2A). The function of this NTS at synapses is not known. While BAI1 promotes the formation and growth of spines and excitatory synapses through the synaptic recruitment of the Par3/Tiam1 polarity complex (Duman et al., 2013) and the stabilization of PDS-95 (Zhu et al., 2015), it is not clear whether these functions are regulated in response to extracellular cues through transmembrane signaling, and no synaptic ligands have yet been identified for BAI1. To determine whether BAI1's extracellular NTS is necessary for its prosynaptogenic and prospinogenic functions, we generated a BAI1 N-terminal deletion mutant $(\mathrm{B} 1 \Delta \mathrm{N}) . \mathrm{B} 1 \Delta \mathrm{N}$ lacks amino acids $125-880$, retaining BAI1's N-terminal signal peptide (amino acids 1-30), but removing all known signaling domains and motifs present N-terminal to the cleavage site on the GAIN domain (i.e., the NTS; Fig. 2A) (Arac et al., 2012). Using a C-terminal-directed polyclonal BAI1 antibody (Duman et al., 2013), we confirmed expression of B1 $\Delta \mathrm{N}$ by WB (Fig. $2 B$ ) and immunofluorescence (Fig. $2 C$ ). As predicted, the molecular weight of the $\mathrm{B} 1 \Delta \mathrm{N}$ mutant was $\sim 90 \mathrm{kDa}$ (828 amino acids) (Fig. $2 B$ ). Using a cell-surface immunostaining protocol on nonpermeabilized cells (i.e., cells fixed in the absence of $0.1 \%$ Triton$\mathrm{X}$ ), we also verified that Flag-tagged BAI1 and $\mathrm{B} 1 \Delta \mathrm{N}$ were both expressed at the cell surface (Fig. $2 A, C$ ). Thus, the absence of the NTS does not prevent $\mathrm{B} 1 \Delta \mathrm{N}$ from localizing to the plasma membrane.

To assess the function of BAIl's NTS in spinogenesis, we next tested the ability of $\mathrm{B} 1 \Delta \mathrm{N}$ to rescue the defects in spine development arising from BAI1 Kd. Dissociated hippocampal neurons cultured for 6-8 days in vitro (DIV) were transfected with EGFP with or without BAIl-directed shRNA in combination with empty control vector (Vec), shRNA-resistant BAI1 (B1), or $\mathrm{B} 1 \Delta \mathrm{N}$. On DIV 21, neurons were fixed and analyzed for BAI1 staining and spine morphology. Compared with control neurons (Vec), BAI1 Kd neurons (B1 Kd+Vec) exhibited a robust loss of BAI1 (Fig. 2D), a decrease in spine density (Fig. 2 D, E; $p<0.001$, $t=-4.05 ; p<0.001, F_{(3,210)}=9.5$, one-way ANOVA), an increase in spine length $\left(p=0.044, t=2.64 ; F_{(3,183)}=6.65\right.$, oneway ANOVA), and a reduction in spine head size $(p=0.036, t=$ $-2.72 ; F_{(3,153)}=7.01$, one-way ANOVA) (Fig. $\left.2 D, F, G\right)$, similar to that observed in vivo. Whereas full-length BAI1 effectively rescued all of these spine phenotypes (Fig. $2 D-G$; density, $p=0.794$, $t=-0.92$; length, $p>0.999, t=-0.08$; maximum diameter, $p=$ $0.914, t=0.65), \mathrm{B} 1 \Delta \mathrm{N}$ failed to rescue, with all measured spine parameters remaining statistically indistinguishable from those in BAI1 Kd neurons (Fig. $2 D-G ; p>0.999$, density, $t=-0.02$; length, $p=0.887, t=0.72$; maximum diameter, $p=0.994, t=$ $-0.26)$ despite similar levels of full-length BAI1 and B1 $\Delta \mathrm{N}$ expression in dendrites (Fig. 2D).

To determine the function of BAI1's NTS in excitatory synaptogenesis, we also quantified the ability of $\mathrm{B} 1 \Delta \mathrm{N}$ to rescue excitatory synapse loss caused by BAI1 Kd (Duman et al., 2013). Synapses were identified by immunostaining the presynaptic marker vesicular glutamate transporter 1 (vGluT1) and the postsynaptic marker PSD-95 and detecting the overlap between these signals. Consistent with our previous results, we found that BAI1 $\mathrm{Kd}$ decreased excitatory synapse density $(p=0.027, t=-2.86$; $p<0.001, F_{(3,84)}=6.72$, one-way ANOVA), which was rescued by RNAi-resistant BAI1 (Fig. $3 A, B ; p=0.982, t=0.37$ ) (Duman et al., 2013). In contrast, $\mathrm{B} 1 \Delta \mathrm{N}$ failed to rescue synaptic density (Fig. $3 A, B ; p>0.999, t=-0.03$ ). Together, these data suggest that the NTS of BAI1 is essential for its ability to promote both spinogenesis and excitatory synaptogenesis.

\section{Activation of BAI1 by its Stachel sequence promotes spine and synapse development via Racl activation}

As BAIl's NTS is required for spinogenesis and synaptogenesis (Figs. 2, 3), we surmised that it contains binding domains through which BAI1 responds to signals. However, to date, there are no verified synaptic BAI1 ligands. Therefore, we used an alternative strategy to manipulate BAI1 activation and determine how signal transduction through BAIl might affect spine and synapse development. Since Liebscher et al. (2014) first reported activation of A-GPCRs via cryptic Stachel autoagonists, this mechanism has proven to be a powerful and generally applicable means to activate A-GPCR-dependent signaling independent of exogenous ligands. Stachel peptides occur in almost all A-GPCRs and share a stereotypical sequence motif (Fig. 4A) (Liebscher et al., 2014). They reside just C-terminal of the GPS cut site within an A-GPCR's GAIN domain. Current models posit that structural changes induced by ligand binding "unmask" the Stachel sequence, allowing it to bind the GPCR moiety of the A-GPCR and activate it. Moreover, peptide mimics of Stachel sequences can activate A-GPCR signaling with varying degrees of specificity (Liebscher et al., 2014; Demberg et al., 2017). BAIl's GAIN domain contains a Stachel sequence conforming to the motif identified by Liebscher et al. (2014) and others. Therefore, to test the consequences of BAIl activation on spinogenesis, we designed a Stachel peptide for BAI1 according to the parameters reported for other A-GPCRs with verified Stachel signaling. The BAI1-Stachel active peptide is 19 amino acids long (Act; STFAILAQLSADANMEKAT) and was optimized considering solubility, length, and positional design as determined empirically by Liebscher et al. (2014) (Fig. 4A). Notably, the conserved phenylalanine (F) and leucine (L) residues in the BAI1-Stachel sequence align with established Stachel sequences from other A-GPCRs, such as GPR56, GPR126, and GPR133 (Fig. 4A) (Liebscher et al., 2014; Stoveken et al., 2015).

To assess the effects of Stachel-induced BAI1 activation on spinogenesis, we incubated developing 15 DIV GFP-expressing 


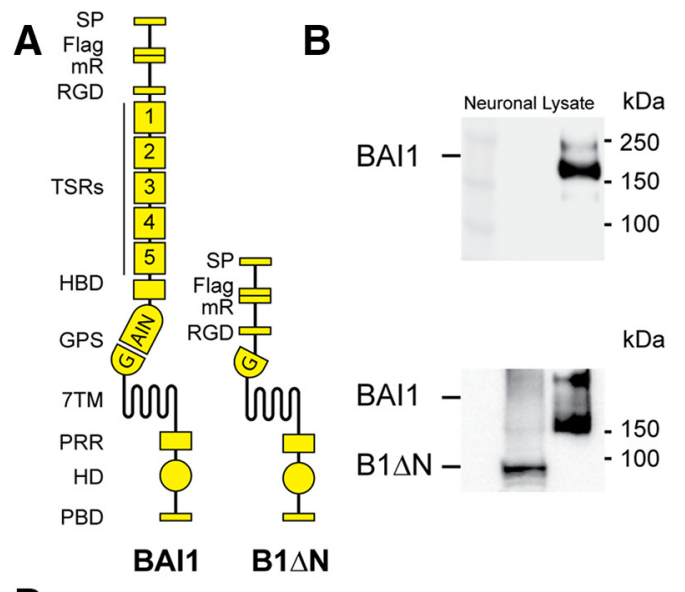

D
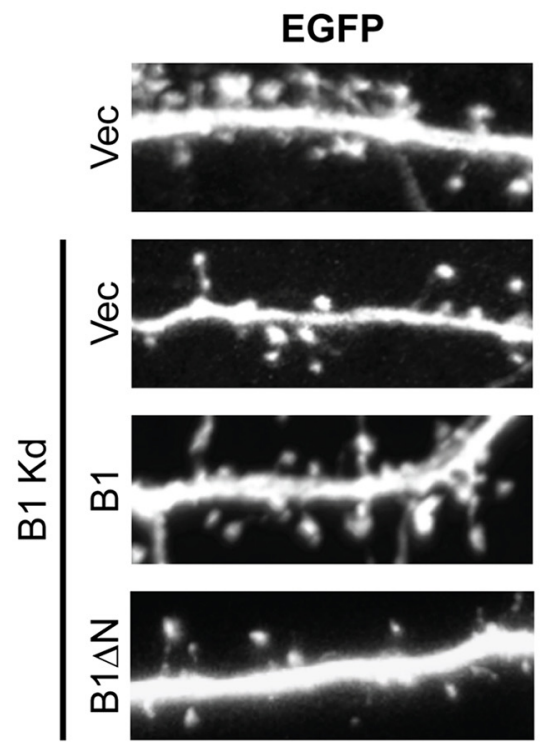

C

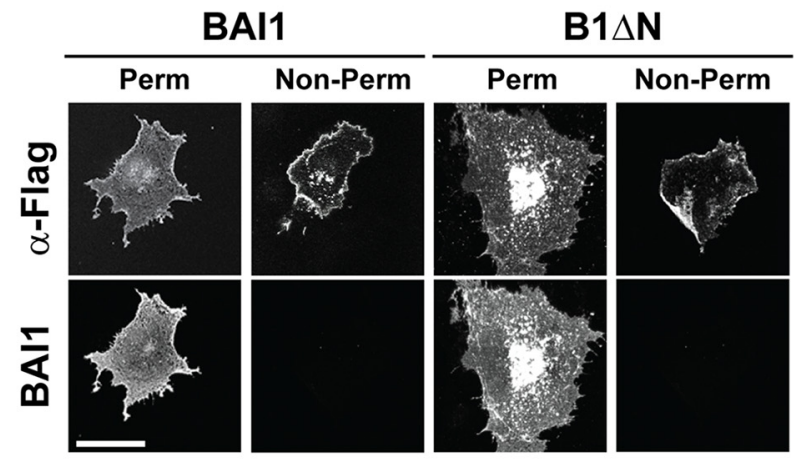

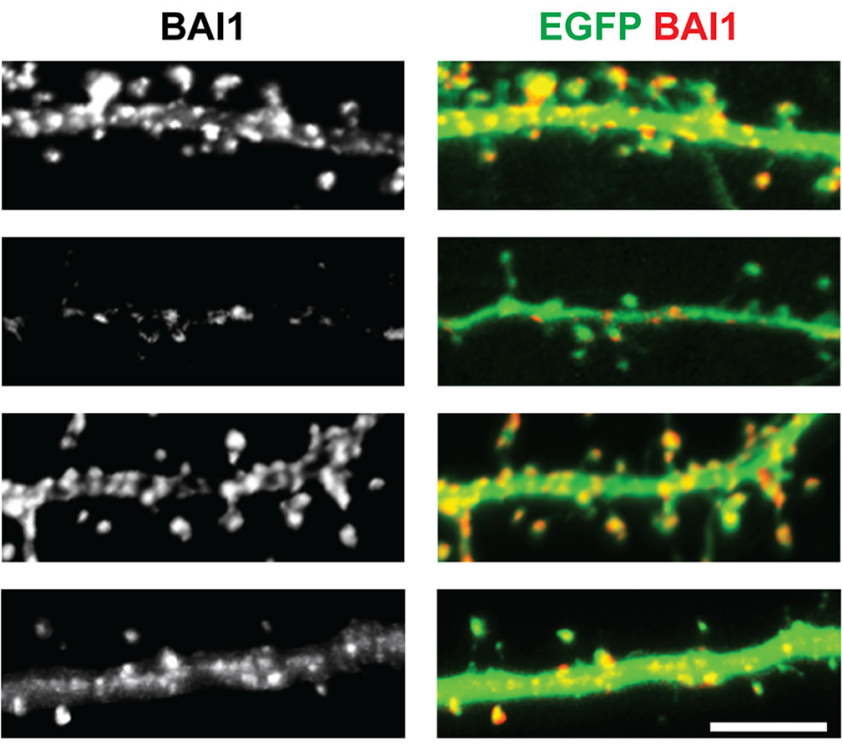
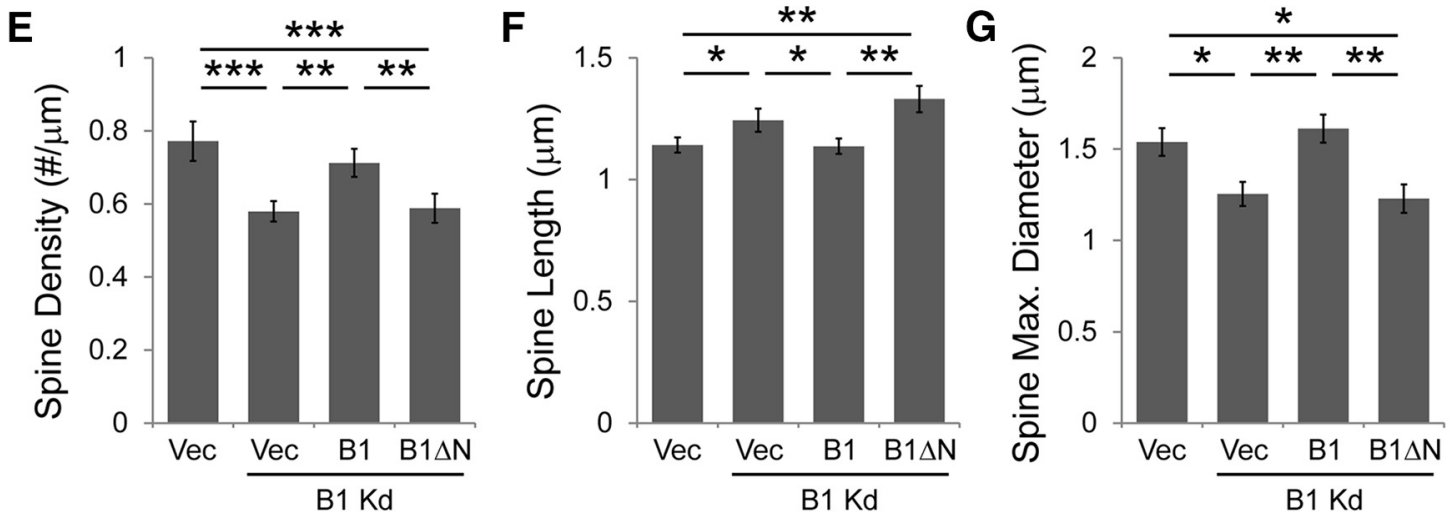

Figure 2. The extracellular NTS of BAl1 is essential for its prospinogenic function. $A$, Schematic of full-length BAI1 and the B1 $\Delta N$ construct. B1 $\Delta N$ was constructed by removing the N-terminal amino acids $125-880$ of BAl1 but keeping its signal peptide (SP) (amino acids 1-30). BAl1 contains numerous signaling domains, including an RGD motif, 5 TSRs, a hormone binding domain (HBD), a G protein proteolysis site (GPS) contained in a GAIN domain, a characteristic GPCR seven-transmembrane domain (7TM), a proline-rich domain (PRR), a helical domain (HD), and a PDZ-binding domain (PBD). A Flag tag and an mRuby2 (mR) fluorescent protein were also added in between the RGD motif and the first TSR for use in only the surface expression experiment (C). $\boldsymbol{B}$, WB analysis of the following: Top, The 21 DIV hippocampal neuronal lysate. BAl1 appears as a characteristic double band indicating full-length BAl1 and BAl1 truncated by MMP-14 (Cork et al., 2012 ). Bottom, Whole-cell lysates from HEK $293 \mathrm{~T}$ cells expressing full-length BAl1 or the B1 $\Delta \mathrm{N}$ mutant. B1 $\Delta \mathrm{N}$ runs at the predicted molecular weight of $80-90 \mathrm{kDa}(828$ amino acids). C, Immunostaining of COS-7 cells expressing N-terminally Flag-tagged BAI1 constructs. Nonpermeabilized (Non-Perm) and permeabilized (Perm) COS-7 cells expressing full-length BAl1 or B1 $\Delta$ N were probed after fixation with antibodies against Flag or BAl1 (targeting the cytoplasmic region of BAl1). Surface staining of both BAl1 constructs can be seen in the nonpermeabilized cells using the anti-flag antibodies. Scale bar, $5 \mu \mathrm{m}$. D, Representative images of secondary dendrites from 21 DIV rat hippocampal neurons used in BAl1 Kd-rescue experiments to assess the requirement for BAl1's extracellular NTS in spinogenesis. Hippocampal neurons expressing EGFP and either pSuper control vector (Vec) or BAl1-directed shRNA (B1 Kd) along with empty expression vector, full-length shRNA-resistant BAl1 (B1), or B1 $\Delta N$. Neurons were stained for BAl1 to confirm rescue expression levels of BAl1 constructs match that of endogenous BAl1. Scale bar, $5 \mu$ m. $E-G$, Quantification of dendritic spine density $(\boldsymbol{E})\left(p<0.001, F_{(3,210)}=9.5\right.$, one-way ANOVA), spine length $(\boldsymbol{F})\left(p<0.001, F_{(3,183)}=6.65\right.$, one-way ANOVA), and spine maximum diameter $(\boldsymbol{G})\left(p<0.001, F_{(3,153)}=7.01\right.$, one-way ANOVA). $N=9$ independent culture preparations; $n=45-67$ neurons per condition. Full-length BAl1 effectively rescued all of the spine phenotypes seen in BAl1 Kd neurons (density pairwise vs WT, $p=$ $0.794, t=-0.92$; length pairwise vs WT, $p>0.999, t=-0.08$; maximum diameter pairwise vs WT, $p=0.914, t=0.65$; Tukey post hoc correction), whereas B1 $\Delta \mathrm{N}$ (Figure legend continues.) 
A
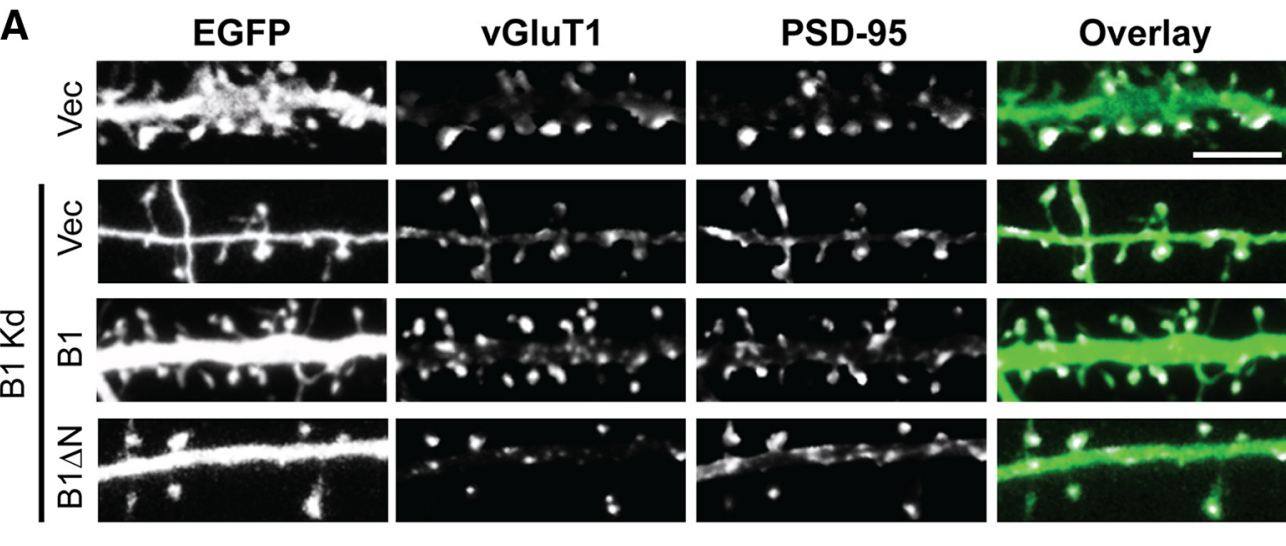

B

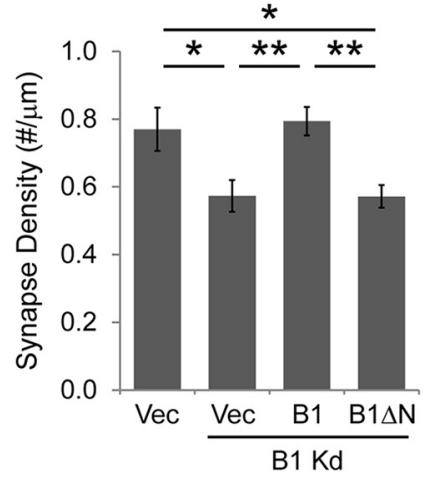

Figure 3. BAl1 requires its extracellular NTS for its prosynaptogenic function. $A$, Representative images from BAl1 Kd-rescue experiments analyzing the function of BAl1's $N$ terminus in BAI1-mediated synaptogenesis. The 21 DIV hippocampal neurons expressing EGFP and either pSuper vector (Vec) or BAI1 shRNA (B1 Kd) along with control vector, B1, or B1 $\Delta \mathrm{N}$ were stained for the presynaptic marker vGluT1 and the postsynaptic marker PSD-95. Overlapping vGluT1/PSD-95 staining (represented as white on the overlay panels in the fourth column), determined using Pearson's correlation (Imaris), was used to mark excitatory synapses on EGFP-expressing neurons. Scale bar, $5 \mu \mathrm{m}$. B, Quantification of excitatory synapse density. Full-length shRNA-resistant BAI 1 transfected between 6 and 8 DIV successfully rescued the synapse density defect seen in 21 DIV BAI1 Kd neurons, whereas the B1 $\Delta \mathrm{N}$ mutant did not rescue (pairwise $p=0.004$ vs Kd, $p=0.006$ vs B1 $\Delta \mathrm{N}$ rescue, $p=0.982$ vs B1 rescue, Tukey post hoc correction; $p<0.001, F_{(3,84)}=6.72$, one-way ANOVA; $N=4$ independent experiments; $n=18-29$ neurons). Data are mean \pm SEM. ${ }^{*} p<0.05$, ${ }^{* *} p<0.01$.

hippocampal neurons with the BAI1-Stachel active (Act) peptide for $1 \mathrm{~h}$. This brief BAI1-Stachel treatment significantly increased spine density compared with treatment with a scrambled control peptide (Scr; ATLAMDSATNAIQSAELFK) (Fig. $4 B, C ; p=$ $0.021, t=2.93)$. Importantly, the BAI1-Stachel-induced increase in spine density was ablated in BAI1 Kd neurons $(p=0.745, t=$ -1.01 ), suggesting that this effect is BAI1-dependent (Fig. $4 B, C$; $p<0.001, F_{(1,98)}=43.12$ for B1 Kd only, $p=0.138, F_{(1,98)}=2.24$ for Stachel only, $p=0.005, F_{(1,98)}=8.12$ for interaction, two-way ANOVA). Unlike spine density, the BAI1-Stachel peptide had no effect on spine length $(p=0.999, t=0.12$, Scr vs Act; $p=0.585$, $t=1.27$, B1 Kd Scr vs Act), suggesting that Stachel-dependent mechanisms account for only part of BAI1's prospinogenic properties (Fig. $4 D ; p<0.001, F_{(1,97)}=23.91$ for B1 Kd only, $p=0.35$, $F_{(1,97)}=0.88$ for Stachel only, two-way ANOVA). Concurrently with its effects on spine density, treatment of 15 DIV hippocampal neurons with the BAI1-Stachel peptide significantly increased excitatory synapse density, and this effect was also dependent on the presence of BAI1 (Fig. $4 E$, F; Scr vs Act, $p=0.009, t=3.27$; B1 Kd Scr vs Act, $p=0.981, t=-0.38 ; p<0.001, F_{(1,64)}=19.5918$ for B1 Kd only, $p=0.0456, F_{(1,64)}=4.1537$ for Stachel only, $p=$

$\leftarrow$

(Figure legend continued.) was unsuccessful at rescuing BAI1 Kd neuron spine deficits (density pairwise vs WT, $p<0.001, t=-4.03$; length pairwise vs WT, $p=0.003, t=3.5$; maximum diameter pairwise vs WT, $p=0.023, t=-2.88$; Tukey post hoc correction). Data are mean \pm SEM. ${ }^{*} p<0.05,{ }^{* *} p<0.01,{ }^{* * *} p<0.001$.
$0.01215, F_{(1,64)}=6.663$ for interaction, two-way ANOVA). Together, these results suggest that Stachel-induced BAI1 activation elicits spinogenesis and excitatory synaptogenesis in developing hippocampal neurons.

Our previous investigation established the Racl GTPase as a key mediator of BAI1-dependent spine and synapse development (Duman et al., 2013). We thus hypothesized that the BAI1Stachel-induced increase in spine/synapse density is driven by Racl activation. To test this hypothesis, we measured Racl activity in live neurons in response to stimulation with the BAI1Stachel active peptide using the RaichuEV-Racl probe, a FRET biosensor of Racl activation (Komatsu et al., 2011). In 13-14 DIV hippocampal neurons, we detected an increase in Racl activation after a $1 \mathrm{~h}$ treatment with the BAI1-Stachel peptide $(p=$ $0.000167)$ that was not detected in response to treatment with the scrambled control peptide (Fig. $5 A, B ; p>0.05, F=1.46$ for B1 Kd only, $p<0.001, F=13.82$ for Stachel only with $p<0.001, F=$ 12.065 for interaction, two-way ANOVA). Moreover, Rac1 activity was not changed by treatment with either the BAI1-Stachel or the scrambled control peptide in BAI1 Kd neurons $(p=0.9991)$, suggesting that, similar to its effects on spines and synapses, Stachel-induced Racl activation is BAI1-dependent (Fig. 5A,B). Consistent with the known spinogenic effects of activated Rac1 (Govek et al., 2005), longitudinal tracking of dendritic spine head size in these experiments also revealed a BAI1-Stachel-induced increase in spine size in control neurons that was not seen with the scrambled peptide or in BAI1 Kd neurons (Fig. $5 C$; pairwise 


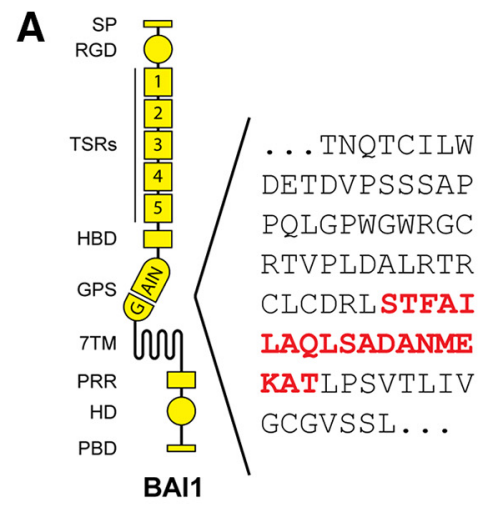

\section{tYFAVLMvSsvev GPR56 tHFGVLMdLprsa GPR126 tNFAILMqVvple GPR133 STFAILAqLsada BAl1}

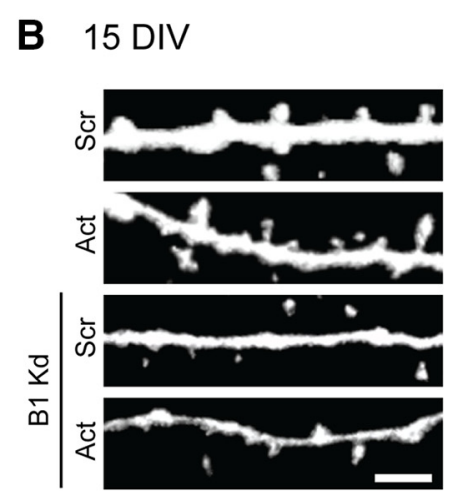

E 15 DIV

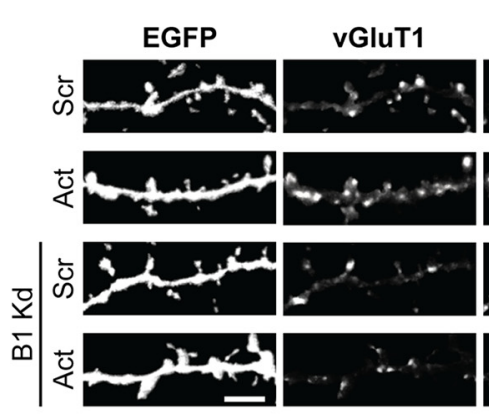

C

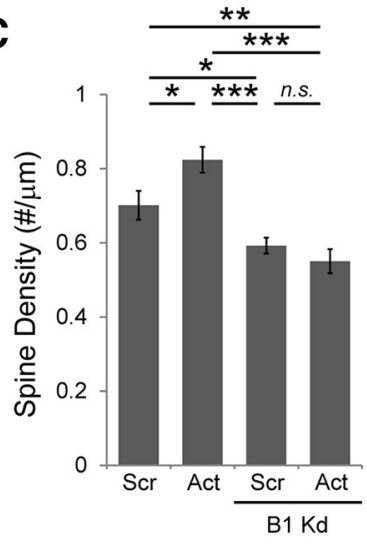

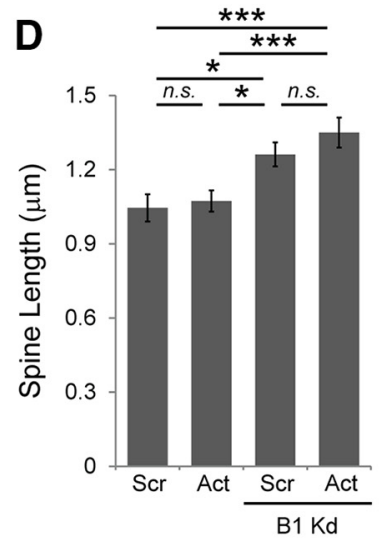

$\mathbf{F}$

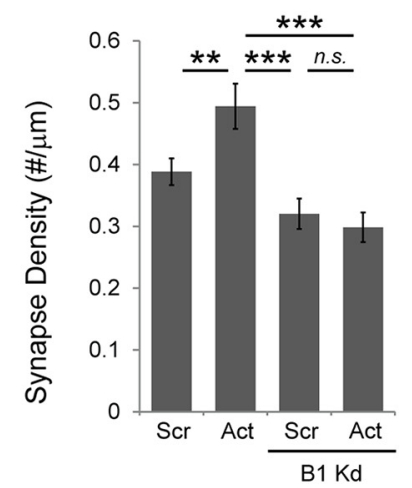

Figure 4. BAl1-Stachel-derived peptide promotes spinogenesis and synaptogenesis in developing 15 DIV hippocampal neurons. A, BAl1 Stachel sequence and alignment compared with empirically tested Stachel sequences for other A-GPCRs. Red highlighted letters on left indicate BAl1 Stachel sequence, whereas capital letters on right indicate key Stachel residues from Liebscher et al. (2014). Red highlighted letters on right indicate conserved or similar key residues in the indicated A-GPCR Stachel sequences. B, Hippocampal neurons were transfected with EGFP and pSuper control vector or BAl1-directed shRNA (BAI1 Kd) at 6 - 8DIV, and then on 15 DIV, neurons were treated with either active BAl1-Stache/ peptide (Act) or scrambled peptide (Scr) for $1 \mathrm{~h}$. Cells were then fixed and imaged, and spines on secondary dendrites (shown in representative images) were subjected to morphometric analysis ( $N=3$ experiments; $n=23-28$ neurons each condition). Scale bar, $5 \mu \mathrm{m}$. C, D, Quantification of 15 DIV hippocampal neuron ( $\boldsymbol{C}$ ) spine density and (D) spine length. Treatment of control neurons with BAl1-Stache/ peptide (Act), but not scrambled peptide (Scr), increased spine density $(p=0.021, t=2.93$, two-way ANOVA with Tukey posthoc correction). This Stachel-induced increase was ablated by BAl1 Kd $(p=0.745, t=-1.01$, two-way ANOVA with Tukey post hoc correction), suggesting BAl1 dependence. $\boldsymbol{E}$, Hippocampal neurons from $\boldsymbol{B}$ were fixed and stained for the presynaptic marker vGluT1 and the postsynaptic marker PSD-95, and overlapping vGluT1/PSD-95 puncta (shown in white in the fourth column) were used to quantify excitatory synapse density on transfected cells. Shown are representative secondary dendrites used for quantification. Scale bar, $5 \mu$ m. $\boldsymbol{F}$, Quantification of excitatory synapse density on 15 DIV hippocampal neurons treated with BAl1-Stachel (Act) or Scrambled (Scr) peptide. Similar to spine density, the BAl1-Stachel peptide increased excitatory synapse density, but this effect was ablated by BAl1 Kd (Scr vs Act, $p=0.009, t=3.27 ; \mathrm{Kd} \mathrm{Scrvs} \mathrm{Act,} p=0.981, t=-0.38 ; p<0.001, F_{(1,64)}=$ 19.5918 for Kd only; $p=0.0456, F_{(1,64)}=4.1537$ for Stachel only; $p=0.01215, F_{(1,64)}=6.663$ for Kd-Stachel interaction, two-way ANOVA; $N=3$ experiments; $n=17$ neurons each condition). Data are mean \pm SEM. ${ }^{*} p<0.05,{ }^{* *} p<0.01,{ }^{* * *} p<0.001$. Not significant $(p>0.05)$.

Act vs Scr, $p=0.006$; pairwise Act vs Kd Scr, $p=0.029)$. Notably, the BAI1-Stachel peptide was unable to increase spine density or Racl activation in mature 22 DIV hippocampal neurons (Fig. $5 D-G)$, suggesting the presence of a critical window for its effects on these processes. Together, these results indicate that Stachelinduced BAI1 activation during development drives Rac1mediated spinogenesis.
BAI1 induces clustering of the presynaptic protein vGluT1 via trans-synaptic signaling

The postsynaptic localization of BAI1 coupled with its multidomain N-terminal extracellular segment suggests that, in addition to mediating postsynaptic development (Duman et al., 2013; Zhu et al., 2015) (Figs. 1-5), BAI1 may interact with binding partners in the synaptic cleft and induce reverse trans-synaptic signaling 


\section{A 15 DIV}
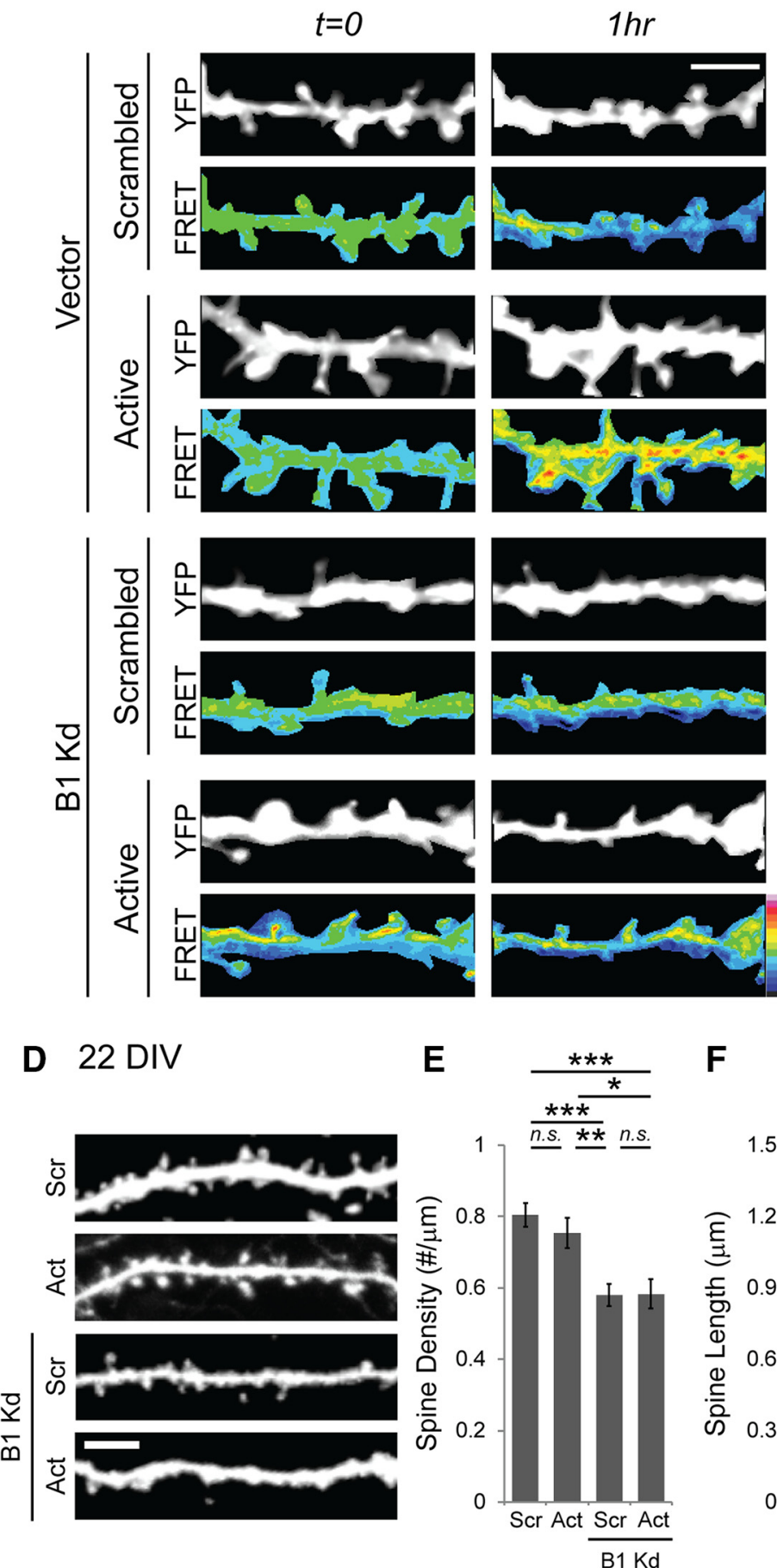

B

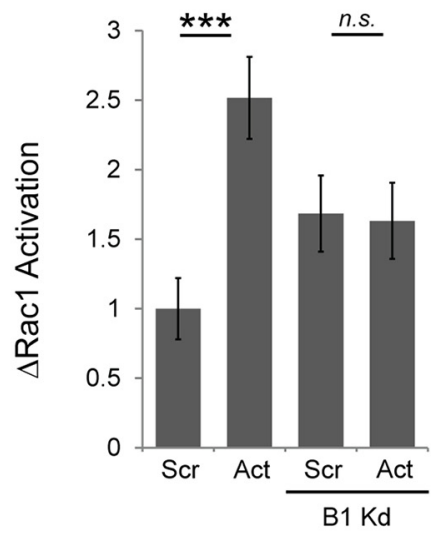

C

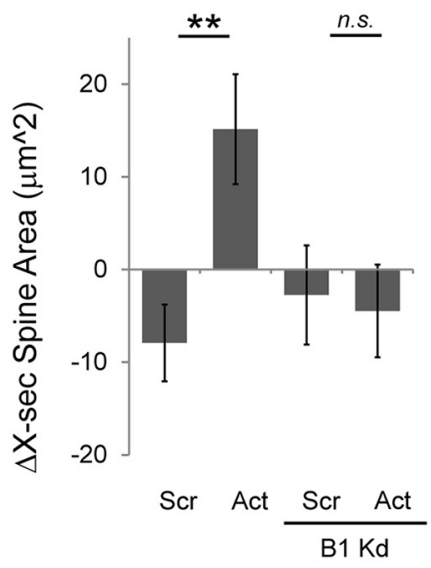

$\mathbf{F}$

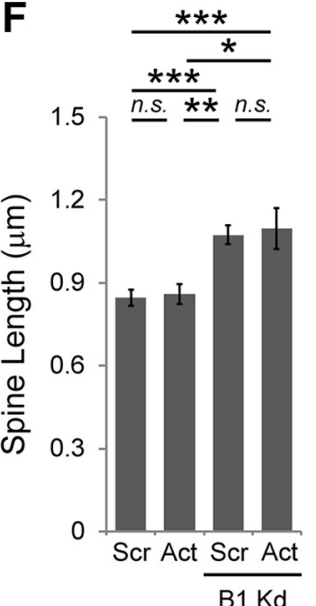

Figure 5. BAl1-Stachel treatment of 15, but not 22, DIV hippocampal neurons increases Rac1 activation in dendritic spines. $A$, Representative images showing the effects of BAl1-Stachel treatment on Rac1 activation. Rac1 activity was measured in live 14 DIV rat hippocampal neurons expressing the RaichuEV-Rac1 FRET probe. Neurons were imaged before and after a $1 \mathrm{~h}$ treatment with the BAl1-Stachel (Active) or Scrambled peptide. Secondary dendrites were visualized by direct excitation of the YFP acceptor(YFP), and Rac1 activity was measured using FRET normalized to the expression level of the RaichuEV-Rac1 probe (FRET). Rac1 activity level was color-coded using the scale (bottom right corner) with white representing higher activation and black representing lower activation. Scale bar, $5 \mu \mathrm{m}$. B, Quantification of change in Rac1 activation. The BAl1-Stache/peptide increased Rac1 activation in 14 DIV control neurons, butnotin BAl1 Kd neurons (pairwiseScrvs Act, $p=0.000167 ;$ pairwise Kd Scrvs Act, $p>0.05, F=1.46$ for shRNA only; $p<0.001, F=13.82$ for Stachel only; with $p<0.001, F=12.065$ for interaction, two-way ANOVA; $N=6$ experiments; $n=5-7$ neurons each; $50-60$ spines each). $C$, Quantification of change in cross-sectional spine head area. BAI1-Stachel increased the cross-sectional area of spines in control neurons, but this effect was dependent on BAl1 (pairwise Scr vs Act, $p=0.006$; pairwise Act vs Kd Scr, $p=$ $0.029 ; N=6$ experiments; $n=5-7$ neurons each; $50-53$ spines each). D, The 22 DIV hippocampal neurons transfected, as in Figure 4B, were treated with the BAl1-Stachel (Act) or scrambled (Scr) peptide for $1 \mathrm{~h}$, and then fixed, imaged, and analyzed as in Figure $4 B(N=3$ independent experiments; $n=15-27$ neurons each). Scale bar, $5 \mu \mathrm{m}$. $\boldsymbol{E}$, $\boldsymbol{F}$, Quantification of 22 DIV hippocampal neuron (E) spine density and (F) spine length. As expected, BAl1 Kd reduced spine density and increased spine length. However, at this age, peptide treatment did not affect either parameter. G, The 22 DIV hippocampal neurons transfected as in $A$. Rac1 activity was measured in live 14 DIV rat hippocampal neurons expressing the RaichuEV-Rac1 FRET probe. Neurons were imaged before and after a $1 \mathrm{~h}$ treatment with the BAl1-Stachel (Active) or Scrambled peptide. Secondary dendrites were visualized by direct excitation of the YFP acceptor (YFP), and Rac1 activity was measured using FRET normalized to the expression level of the RaichuEV-Rac1 probe (FRET). Quantification of changes in Rac1 activation is shown. BAl1-Stachel did not increase Rac1 activation in control neurons, and also not in BAl1 Kd neurons (pairwise Scr vs Act, $p=0.0000209$; pairwise Kd Scrvs Act, $p=0.265 ; F=4.30, p=0.04$ for shRNA only; $F=20.91, p=0.00001$ for Stachel only; with $F=21.41, p=0.00001$ for interaction, two-way ANOVA; $N=5$ experiments; $n=5-7$ neurons each experiment; 20 spines each neuron). ${ }^{* *}$ Significant difference compared with all other conditions $(p<0.001)$. Data are mean \pm SEM. ${ }^{*} p<0.05,{ }^{* *} p<0.01,{ }^{* * *} p<0.001$. Not significant $(p>0.05)$. 
A 6 DIV
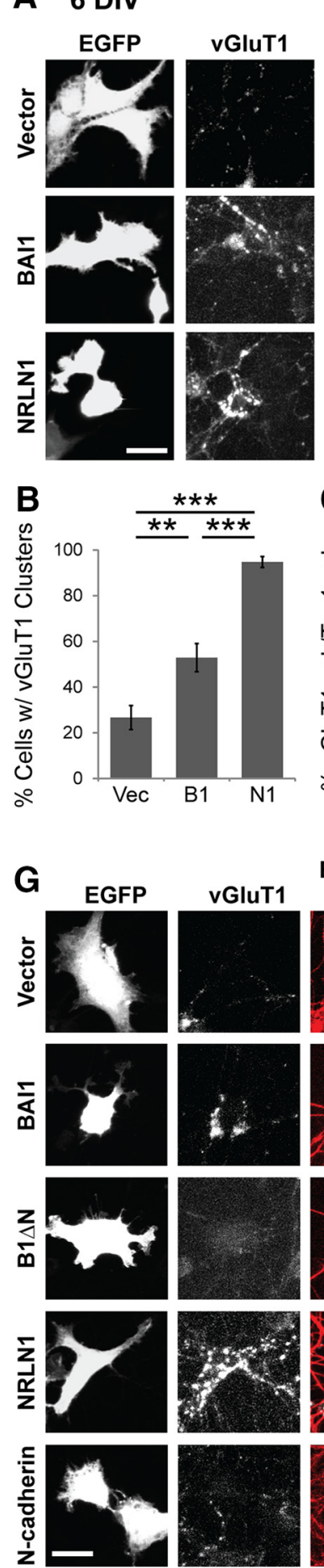

E+V Co-Loc vGluT1 Tau1
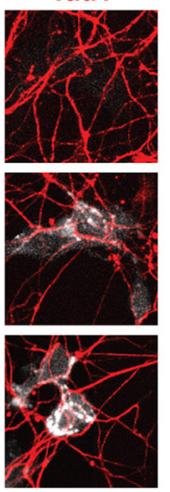

C
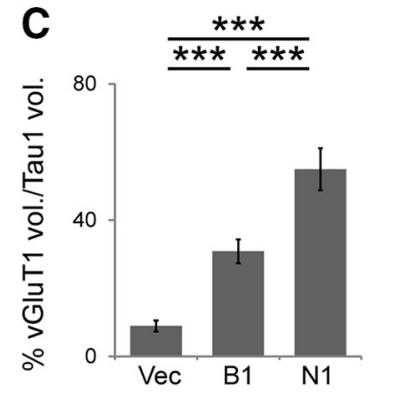

EGFP

E+V Co-loc vGluT1 Tau1

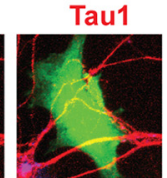

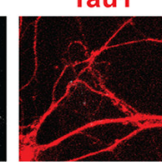
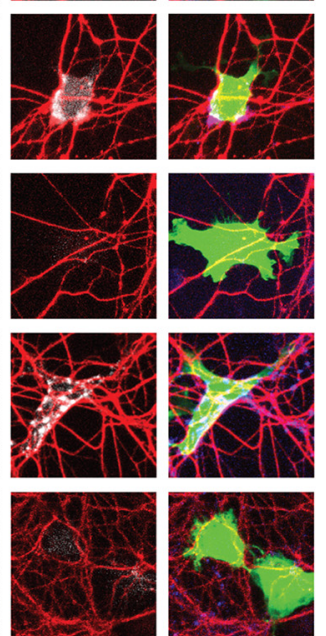
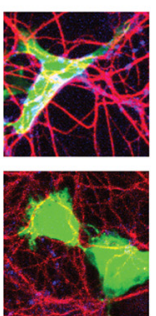
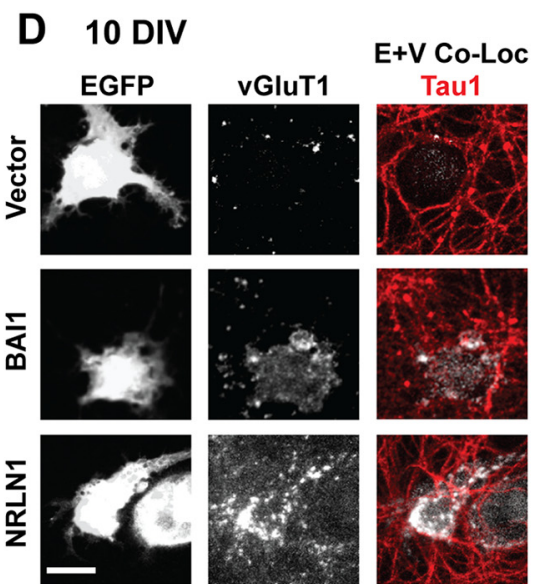

EGFP

vGluT1

Tau1
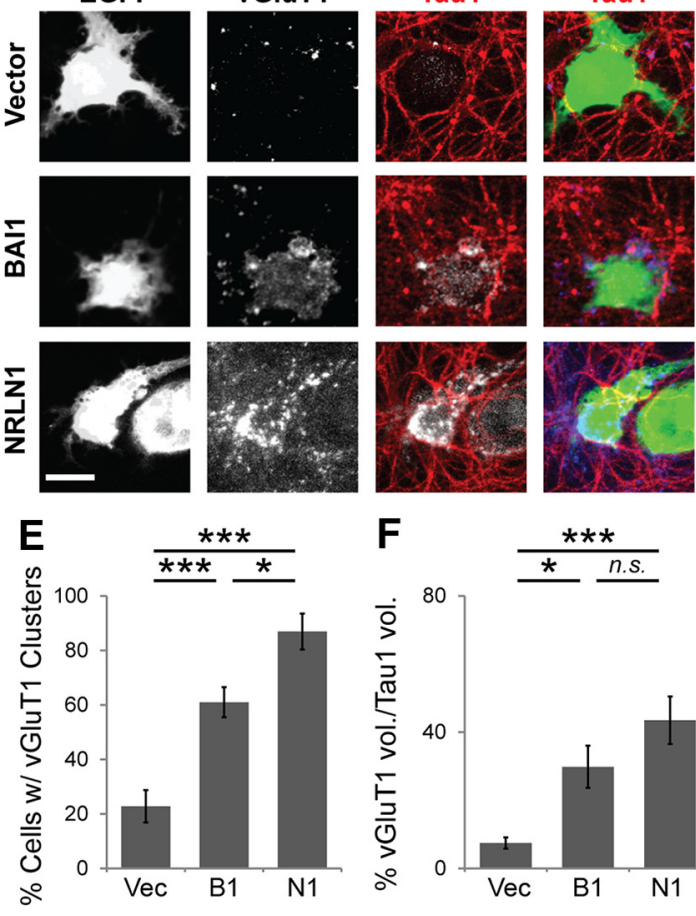

$\mathbf{F} \quad \frac{\star * *}{\star n . S .}$

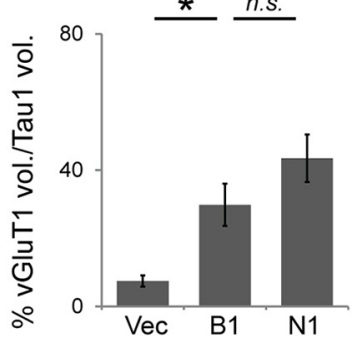

H

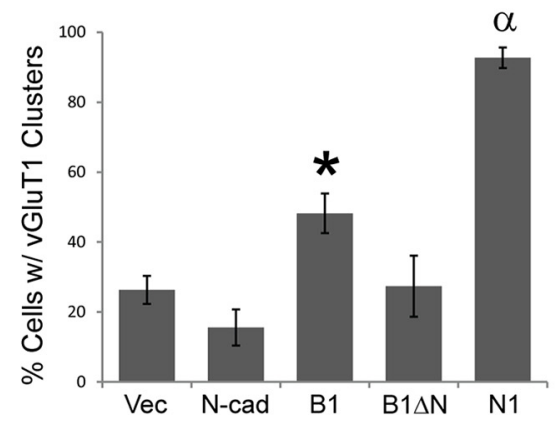

I

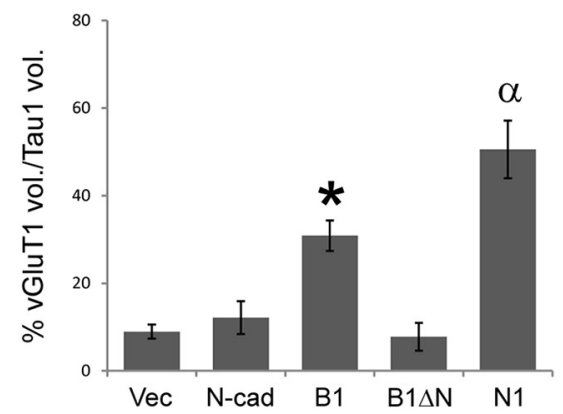

Figure 6. BAl1 induces clustering of the presynaptic protein vGluT1. A, Representative images of a 6 DIV mixed-culture assay showing COS7 cells expressing EGFP and control vector, BAl1, or NRLN1 cocultured with 6 DIV hippocampal neurons. Transfected COS7 cells were layered on 5 DIV neurons, and the next day the cultures were fixed and stained for the axon marker Tau1 (red) and the presynaptic marker vGluT1 (blue). Axons contacting EGFP-expressing COS7 (E+V Co-Loc) were assayed for the presence of clustered vGluT1 (blue), indicating presynaptic differentiation. Scale bar, $5 \mu \mathrm{m}$. B, Quantification of 6 DIV mixed-cultures in $\boldsymbol{A}$ to assess the percentage of GFP-expressing COS7 cells colocalized with axons that are positive for vGluT1 clusters. Compared with control cells (Vec), a higher percentage of both BAl1-expressing (B1) and NRLN1-expressing (N1) COS7 cells contacted axons with vGluT1 clusters (Vec vs B1, $p=0.002, t=4.17$; Vec vs N1, $p<0.001, t=$ $10.82 ; p<0.001, F_{(2,15)}=59.61$, one-way ANOVA; $N=6$ experiments; $n=10$ frames each). $C$, Quantification of 6 DIV mixed-cultures in $A$ to determine the percentage volume of Tau1-stained axons on GFP-expressing COS7 cells that are positive for vGluT1 clusters. Axons contacting either BAl1-expressing or NRLN1-expressing COS7 cells possessed a higher percentage of vGluT1 clusters than axons contacting vector-only-expressing cells (Vec vs $B 1, p=0.001, t=3.75 ;$ Vec vs $N 1, p<0.001, t=7.99 ; p<0.001, F_{(2,53)}=31.92$, one-way ANOVA; $N=3 ; n=18$ or 19 frames each). $\boldsymbol{D}$, Representative images of a $10 \mathrm{DIV}$ mixed-culture assay. COS7 cells were transfected as in $\boldsymbol{A}$ but layered on top of 9 DIV neurons, with cultures fixed at $10 \mathrm{DIV}$. Scale bar, $5 \mu \mathrm{m}$. $\boldsymbol{E}$, Quantification of 10 DIV mixed-cultures in $\boldsymbol{D}$ to assess the percentage of GFP-expressing COS7 cells colocalized with axons that are positive for vGluT1 clusters. Compared with control COS7 cells (Vec), a higher percentage of BAl1-expressing (B1) and NRLN1-expressing (N1) COS7 cells are associated with axons containing vGluT1 clusters (Vec vs B1, $p=0.001, t=4.91 ; \mathrm{Vec} v \mathrm{~N} \mathrm{N1}, p<0.001, t=8.25 ; p<$ $0.001, F_{(2,15)}=34.45$, one-way ANOVA; $N=6 ; n=10$ frames each). $F$, Quantification of 10 DIV mixed-cultures in $\boldsymbol{D}$ to determine the percentage volume of Tau1-stained axons on GFP-expressing COS7 cells that are positive for vGluT1 clusters. Axons contacting both BAl1-expressing and NRLN1-expressing COS7 cells have a higher percentage of vGluT1 (Figure legend continues.) 
that enhances presynaptic terminal differentiation. To examine this possibility, we used a mixed-culture assay system (Biederer and Scheiffele, 2007). This method involves expressing transmembrane proteins in heterologous cells (e.g., COS-7 cells), coculturing the transfected cells with immature hippocampal neurons (to minimize endogenous synaptogenesis), and at sites of contact, assaying the ability of the expressed transmembrane protein in heterologous cells to induce clustering of presynaptic proteins (e.g., vGluT1) on contacting axons as a readout of presynaptic differentiation. As a positive control for this assay, we used NRLN1 $\beta$ (NRLN1), a well-established postsynaptic adhesion protein that robustly promotes both presynaptic and postsynaptic development of excitatory synapses (Scheiffele et al., 2000). NRLN1 drives presynaptic differentiation through transsynaptic signaling mediated via interaction with the presynaptic protein NRXN1 (Scheiffele et al., 2000; Chih et al., 2005; Craig and Kang, 2007; Hu et al., 2015). To assess BAIl's effects in the assay, we layered COS-7 cells expressing EGFP in combination with BAI1, NRLN1, or control vector (pcDNA3.1) on top of 5 or 9 DIV hippocampal neurons. One day later, we fixed and immunostained the cells for the presynaptic marker vGluT1 and the axonal marker Taul (to identify axons). Axons contacting EGFPpositive COS-7 cells were examined for vGluT1 clustering. At both time points (6 and 10 DIV), the percentage of EGFPpositive COS-7 cells associated with axons containing vGluT1 puncta was significantly higher for BAI1-expressing COS-7 cells than for control cells (Fig. $6 A, B ; 6$ DIV Vec vs B1, $p=0.002, t=$ 4.17; 6 DIV Vec vs N1, $p<0.001, t=10.82 ; p<0.001, F_{(2,15)}=$ 59.61, one-way ANOVA; Fig. $6 D, E$; 10 DIV Vec vs $\mathrm{B} 1, p=0.001$, $t=4.91 ; 10$ DIV Vec vs N1, $p<0.001, t=8.25 ; p<0.001, F_{(2,15)}=$ 34.45 , one-way ANOVA). Measuring the percentage of vGluT1 cluster staining overlapping Taul staining on EGFP-positive cells also revealed higher values for BAI1-expressing cells relative to control cells (Fig. 6C; 6 DIV Vec vs B1, $p=0.001, t=3.75 ; 6$ DIV Vec vs N1, $p<0.001, t=7.99 ; p<0.001, F_{(2,53)}=31.92$, one-way ANOVA; Fig. $6 F ; 10$ DIV Vec vs B1, $p=0.013, t=3.06 ; 6$ DIV Vec vs N1, $p<$ $0.001, t=7.99 ; p<0.001, F_{(2,27)}=12.33$, one-way ANOVA). These results indicate that BAI1 induces clustering of the presynaptic protein vGluT1 in immature axons, suggesting that BAI1 promotes presynaptic differentiation.

To test whether BAIl's NTS is required for inducing vGluT1 clustering, we compared $\mathrm{B} 1 \Delta \mathrm{N}$ with full-length BAI1 in the mixed-culture assay. Whereas full-length BAI1-expressing cells stimulated significant vGluT1 clustering on contacting axons,

\footnotetext{
$\leftarrow$

(Figure legend continued.) clusters than axons contacting vector-only-expressing COS7 cells (Vec vs B1, $p=0.013, t=3.06 ;$ Vec vs N1, $p<0.001, t=7.99 ; p<0.001, F_{(2,27)}=12.33$, one-way ANOVA; $N=3 ; n=10$ frames each). $G$, Representative images from a 6 DIV mixedculture assay as in $A$, but with two additional conditions (B1 $\Delta N$ and N-cadherin) to assess the specificity of BAl1's effect on presynaptic vGluT1 clustering. Scale bar, $5 \mu \mathrm{m}$. $\boldsymbol{H}$, Quantification of 6 DIV mixed-cultures in $G$, measuring the percentage of GFP-expressing $C O S 7$ cells colocalized with axons positive for vGluT1 clusters. Relative to control (Vec) cells, COS7 cells expressing BAI1 (B1) or NRLN1 (N1) induce significant vGluT1 clustering, whereas COS7 cells expressing $\mathrm{N}$-cadherin ( $\mathrm{N}$-cad) or B1 $\Delta \mathrm{N}$ do not $\left(p<0.001, F_{(4,32)}=34.90\right.$, one-way ANOVA; for pairwise $t$ scores and $p$ values, see Materials and Methods; $N=9 ; n=10$ frames each). Symbols $\left({ }^{*}, \alpha\right)$ represent significant difference compared with all other conditions. I, Quantification of 6 DIV mixed-cultures in $\mathbf{G}$, measuring the percentage volume of Tau ${ }^{+}$axons on GFP-expressing COS7 cells that contain vGluT1 clusters. Axons contacting COS7 cells expressing BAI1 (B1) or NRLN1 (N1) possess a higher percentage of VGluT1 clusters than axons on COS7 cells expressing $\mathrm{N}$-cadherin ( $\mathrm{N}$-cad), B1 $\Delta \mathrm{N}$, or vector $\left(p<0.001, F_{(4,73)}=21.58\right.$, one-way ANOVA; for pairwise $t$ scores and $p$ values, see Materials and Methods; $N=3 ; n=8-19$ frames each). Symbols ( ${ }^{*}$, $\alpha$ ) represent significant difference compared with all other conditions. Data are mean \pm SEM. ${ }^{*} p<0.05,{ }^{* *} p<0.01,{ }^{* * *} p<0.001$. Not significant $(p>0.05)$.
}

B1 $\Delta \mathrm{N}$-expressing COS7 cells failed to do so (Fig. $6 \mathrm{G}-\mathrm{I}$; Fig. $6 \mathrm{H}$ : $p<0.001, F_{(4,32)}=34.90$, one-way ANOVA; Fig. 6I: $p<0.001$, $F_{(4,73)}=21.58$, one-way ANOVA; for pairwise $t$ scores and $p$ values, see Materials and Methods), suggesting that BAIl's NTS is necessary for promoting presynaptic differentiation. To assess the specificity of BAI1's effects on vGluT1 clustering, we also compared BAI1 with N-cadherin, a transmembrane synaptic adhesion protein that does not promote clustering of presynaptic proteins (Biederer and Scheiffele, 2007; Linhoff et al., 2009). In contrast to BAI1-expressing cells, $\mathrm{N}$-cadherin-expressing COS-7 cells had no effect on vGluT1 clustering beyond that observed in vector-only and $\mathrm{B} 1 \Delta \mathrm{N}$-expressing cells (\% positive cells pairwise to vector, $p=0.789, t=-1.13$; pairwise to $\mathrm{B} 1 \Delta \mathrm{N}$, $p=0.751, t=1.20$; vGluT1/Tau1 volume pairwise to vector, $p>0.999, t=0.01$; pairwise to $\mathrm{B} 1 \Delta \mathrm{N}, p>0.999, t=-0.17$ ), confirming the specificity of BAIl's ability to promote presynaptic specialization (Fig. $6 G-I$ ). Together, these results suggest that BAIl signals trans-synaptically via its NTS to induce presynaptic differentiation.

\section{NRLN1 functionally interacts with BAI1 in spines to promote excitatory synapse growth}

The requirement for BAIl's extracellular NTS in promoting both presynaptic and postsynaptic development suggests that it interacts with synaptic partners that serve as its ligand, receptor, and/or coreceptor. Possible synaptic partners of BAI1 include postsynaptic proteins that have similar functions and potential BAI1-binding domains. The postsynaptic adhesion molecule NRLN1 is a particularly strong candidate. NRLN1 is a potent regulator of excitatory synapse formation, maturation, and function that has been implicated in neurodevelopmental disorders, including ASD (Cao and Tabuchi, 2017; Nakanishi et al., 2017). BAI1 and NRLN1 both promote spinogenesis and synaptogenesis (Barrow et al., 2009; Duman et al., 2013, 2016; Hu et al., 2015; Chanda et al., 2017), and our mixed-culture assay demonstrates that they also both induce clustering of presynaptic vGluT1 (Fig. 6). BAIl and NRLN1 also coexpress temporally in the brain, increasing after birth and persisting in adulthood (Song et al., 1999; Koh et al., 2001). Moreover, BAI1 contains potential NRLN1-binding domains, including TSRs that are also present in thrombospondin-1, a protein whose interaction with NRLN1 (mediated by these domains) accelerates excitatory synaptogenesis (Xu et al., 2010). Thus, we asked whether NRLN1 and BAI1 form a complex at postsynaptic terminals, and whether this interaction modulates their functions in the context of spine and synapse development.

Mild overexpression of BAI1, HA-tagged NRLN1, and EGFP in cultured hippocampal neurons confirmed that these proteins colocalize in the heads of dendritic spines (Fig. 7A). To test whether BAI1 and NRLN1 interact, we used HA antibodies to immunoprecipitate HA-tagged NRLN1 or its canonical binding partner NRXN1 (Scheiffele et al., 2000) from HEK293T cells coexpressing BAI1, and then performed $\mathrm{WB}$ analysis to assess coimmunoprecipitation of BAI1. HA-NRLN1 effectively coimmunoprecipitated BAI1, but HA-NRXN1 failed to do so (Fig. $7 B$ ). Reciprocal immunoprecipitations showed similar results: BAI1 successfully coimmunoprecipitated HA-NRLN1 but not HA-NRXN1 (Fig. 7B), suggesting that BAI1 and NRLN1 specifically interact.

Because NRLN1 does not have an extensive C-terminal segment and the TSRs of BAI1 are located on its extracellular NTS, we postulated that BAIl's NTS alone (also called Vasculostatin; Fig. 7C) (Kaur et al., 2005) may be sufficient for mediating the 
A

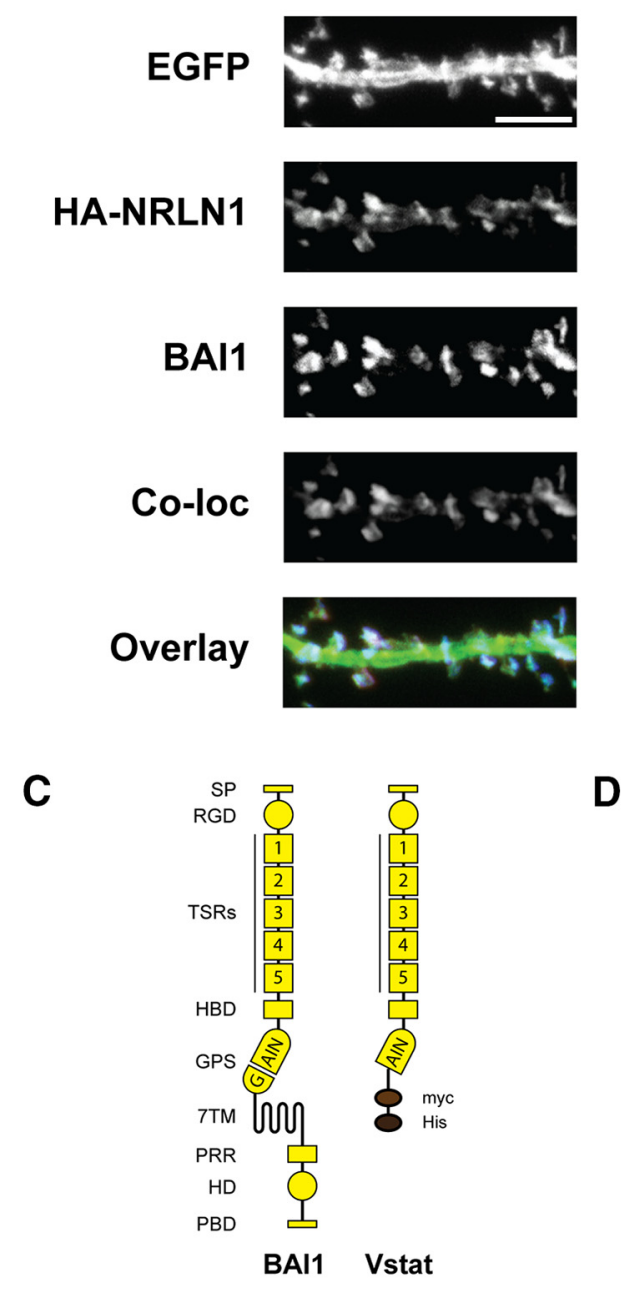

B

$\begin{array}{rrrrrrr}\text { BAl1 } & - & + & - & - & + & + \\ \text { HA-NRXN1 } & - & - & + & - & + & - \\ \text { HA-NRLN1 } & - & - & - & + & - & +\end{array}$

IP: BAI1 $\mid$\begin{tabular}{c|}
$250-$ \\
$150-$ \\
$100-$ \\
$75-$
\end{tabular}
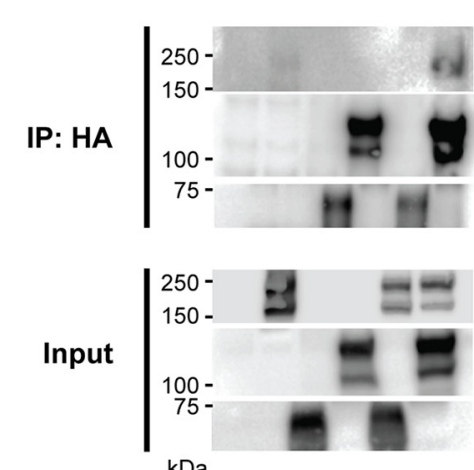

IB:

BAl1

HA-NRLN1

HA-NRXN1

IB:

BAl1

HA-NRLN1

HA-NRXN1

IB:

BAl1

HA-NRLN1

HA-NRXN1

$\mathrm{kDa}$

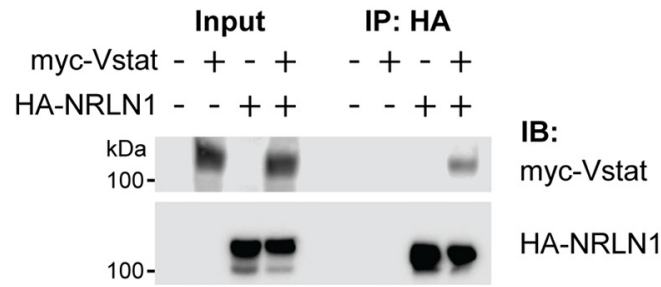

E

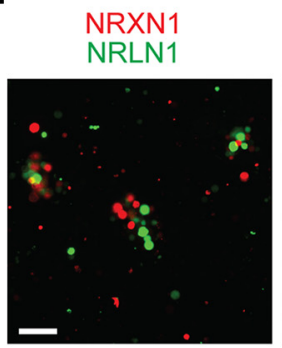

BAI1 NRLN1

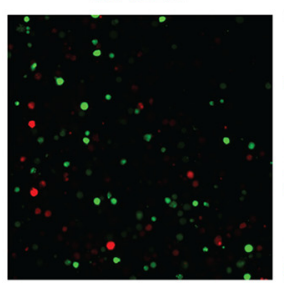

$\mathrm{BAI} 1$ NRXN1

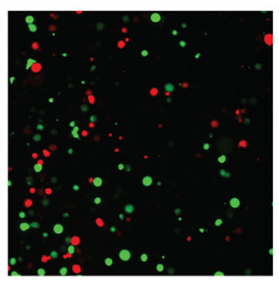

F

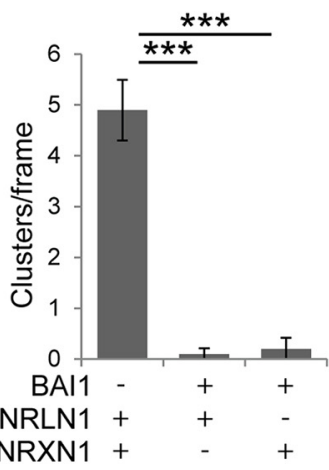

Figure 7. NRLN1 interacts with BAI1 in dendritic spines. $A$, Rat hippocampal neurons (6-8DIV) were transfected with EGFP and low levels of BAI1 and HA-tagged NRLN1, and on 21 DIV the cells were fixed and stained for HA and BAl1. As shown in the representative images, BAI1 (blue in overlay) and NRLN1 (red in overlay) colocalize at spine heads $(N=3)$. Scale bar, $5 \mu \mathrm{m}$. $\boldsymbol{B}, \mathrm{BAl} 1 \mathrm{was}$ coexpressed in HEK293T cells with HA-tagged NRLN1 or HA-tagged NRXN1. Proteins were immunoprecipitated (IP) with either anti-BAl1 or anti-HA antibodies and subjected to WB analysis to determine whether BAl1 interacts with NRLN1 or NRXN1. BAI1 specifically interacts with NRLN1 $(N=4)$. IB, Immunoblot. C, Schematic of full-length BAl1 and myc/His-tagged Vasculostatin (Vstat) composed of the NTS of BAI1.D, HA antibodies were used to immunoprecipitate (IP) HA-tagged NRLN1 from the lysates of HEK293T cells expressing empty vector or HA-tagged NRLN1 in combination with control vector or myc-tagged Vstat. Proteins were then subjected to WB analysis. Myc-Vstat coimmunoprecipitated with HA-NRLN1, demonstrating that BAI1's NTS is sufficient to bind NRLN1 $(N=3)$. IB, Immunoblot. $E$, Representative images from a cell-cell adhesion assay where COS-7 cells expressing GFP or mCherry in combination with NRXN1, NRLN1, or BAI1 were mixed in different combinations and allowed to adhere to one another and form clusters. Scale bar, $5 \mu \mathrm{m}$. $\boldsymbol{F}$, Quantification of the cell-cell adhesion assay in $\boldsymbol{E}$. Clusters of $>4$ cells containing at least one cell of each color were considered a single cluster. BAl1-expressing cells failed to form clusters with either NRXN1- or NRLN1-expressing cells, suggesting that these proteins do not interact in trans. In contrast, NRXN1-expressing cells formed numerous clusters with NRLN1-expressing cells, as expected because they interact trans-synaptically (pairwise NRLN1-BAI1 vs NRLN1-NRXN1, $p<0.001 ;$ pairwise NRXN1-BAl1 vs NRLN1-NRXN1, $p<0.001 ; p<0.001, F_{(2,27)}=64.69$, one-way ANOVA; $N=3$ independent experiments). Data are mean \pm SEM. ${ }^{* * *} p<0.001$. Not significant $(p>0.05)$.

BAI1-NRLN1 interaction. Indeed, coimmunoprecipitation of Vasculostatin with HA-NRLN1 from HEK293T cells demonstrated that HA-NRLN1 interacts with Vasculostatin, indicating that BAIl's N terminus is sufficient to bind to NRLN1 (Fig. 7D).
This result implies that BAI1 could potentially interact with NRLN1 in cis (i.e., in the same cells) or in trans (i.e., in different cells), possibly forming a complex across the synaptic cleft. To investigate whether BAI1 is capable of forming trans-synaptic 
A

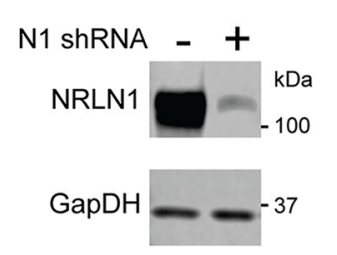

F

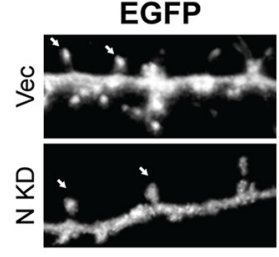

B

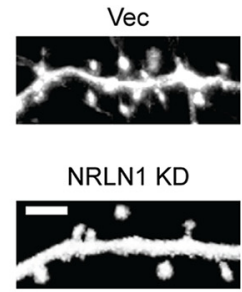

BAI1

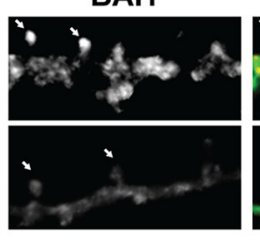

C

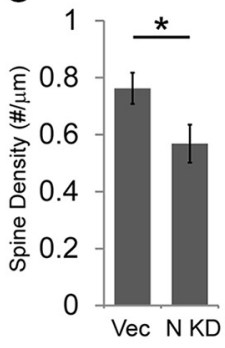

Overlay

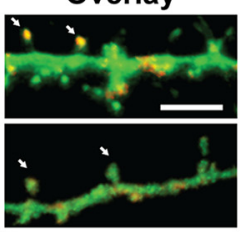

D

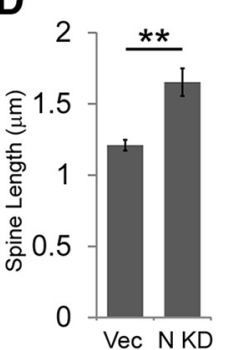

E

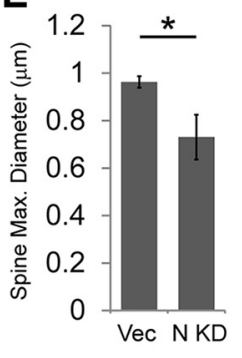

G

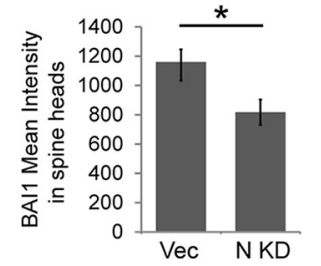

Figure 8. NRLN1 controls BAI1 expression levels at spines. A, Confirmation of NRLN1 Kd. NRLN1 was coexpressed in HEK293T cells with either pSuper vector control or an shRNA targeted toward NRLN1 (N1 shRNA). Lysates were collected and subjected to WB analysis to determine NRLN1 and GapDH levels. NRLN1 expression decreased dramatically upon expression of the N1 shRNA, indicating successful NRLN1 Kd. B, Rat hippocampal neurons (6 DIV) were transfected with EGFP and either empty pSuper vector (Vec) or N1 shRNA (NRLN1 Kd). Shown are representative secondary dendrite images used to analyze key spine parameters. Scale bar, $5 \mu \mathrm{m}$. $\boldsymbol{C}-\boldsymbol{E}$, Quantification of spine density from (B) NRLN1 Kd (N Kd) significantly decreased spine density $(\boldsymbol{C})(p=0.0451$, unpaired $t$ test), increased spine length $(\boldsymbol{D})(p=0.00149$, unpaired $t$ test), and decreased spine maximum diameter $(\boldsymbol{E})(p=0.0434$, unpaired $t$ test $)(N=3 ; n=7-9$ neurons per condition per repeat). $\boldsymbol{F}$, NRLN1 Kd alters BAl1 expression in spine heads. Neurons from $\boldsymbol{B}$ were stained for BAl1 to evaluate any change in BAl1 expression or localization. BAl1 expression at spine heads was measured using Imaris by marking spine heads (as indicated by arrowheads) and measuring mean intensity of BAl1 signal. Scale bar, $5 \mu \mathrm{m}$. G, Quantification of BAl1 expression at spine heads from (F) BAl1 expression is significantly reduced at spine heads after NRLN1 Kd (N Kd) $(p=0.0276$, unpaired $t$ test; $N=3 ; n=27)$. Data are mean \pm SEM. ${ }^{*} p<0.05$, ${ }^{* *} p<0.01$.

interactions with NRLN1 or NRXN1, we used a cell-cell adhesion assay (Woo et al., 2009). Although NRLN1-expressing cells and NRXN1-expressing cells formed significant clusters with one another, neither cell population clustered with BAI1expressing cells. This result suggests that NRLN1 $(p<0.001)$ and NRXN1 $(p<0.001)$ do not interact in trans with BAI1 in a manner comparable with NLRN1-NRXN1 (Fig. 7E,F; $p<$ $0.001, F_{(2,27)}=64.69$, one-way ANOVA). Rather, the interaction between BAI1 and NRLN1 likely occurs in cis at postsynaptic terminals.

Because NRLN1 facilitates the recruitment and stabilization of key synaptic components during synaptogenesis (Gerrow et al., 2006; Barrow et al., 2009; Aiga et al., 2011; Maro et al., 2015), we investigated whether BAI1's synaptic localization depends on NRLN1 expression. As expected, Kd of NRLN1 in hippocampal neurons led to a decrease in spine density $(p=0.0451)$ and spine head diameter $(p=0.0434)$ and an increase in spine length $(p=$ 0.00149 ) (Fig. $8 A-E$ ), consistent with previous reports (Hu et al., 2015). Notably, we found that, relative to control neurons, BAI1 levels in spines significantly decreased upon NRLN1 Kd (Fig. $8 F, G ; p=0.0276$ ), suggesting that proper synaptic localization/ expression of BAIl depends on NRLN1.

Because NRLN1 and BAI1 interact and have similar prospinogenic and prosynaptogenic functions, they may also cooperate and/or modulate each other's ability to regulate these processes. Overexpression of NRLN1 induces robust spine and synapse development (Dahlhaus and El-Husseini, 2010; Dahlhaus et al., 2010; Schnell et al., 2012; Hu et al., 2015). To test whether BAI1 is required for NRLN1-driven spinogenesis/synaptogenesis, we overexpressed NRLN1 in hippocampal neurons with or without BAI1 Kd (B1 Kd). In control neurons, NRLN1 overexpression increased spine density, decreased spine length, and increased spine head maximum diameter (Fig. 9A-D). In neurons in which BAI1 was knocked down, NRLN1 overexpression still increased spine density (WT B1 Kd vs NRLN1 OX B1 Kd, $p<0.001, t=$ 6.14) and decreased spine length (WT B1 Kd vs NRLN1 OX B1
Kd, $p<0.001, t=-5.46$ ) (Fig. 9A-C; Density, Fig. 9B: $p=0.035$, $F_{(1,101)}=4.58$ for BAI1 shRNA only, $p<0.001, F_{(1,101)}=40.54$ for NRLN1 OX only, and $p=0.012, F_{(1,101)}=6.62$ for interaction, two-way ANOVA; Length, Figure $8 C: p=0.028, F_{(1,101)}=$ 4.95 for BAI1 shRNA only, $p<0.001, F_{(1,101)}=34.38$ for NRLN1 OX only, and $p=0.053, F_{(1,101)}=3.8$ for interaction, two-way ANOVA), suggesting that BAI1 is not required for these aspects of NRLN1-induced spinogenesis. However, with BAI1 Kd, NRLN1 overexpression failed to increase spine maximum diameter to its previous extent (WT Vec vs WT Kd, $p=0.021, t=$ -2.94; NRLN1 OX Vec vs NRLN1 OX Kd, $p=0.03, t=-2.80$ ), suggesting that NRLN1 depends on BAI1 to promote spine growth (Fig. $9 D ; p<0.001, F_{(1,100)}=16.45$ for BAI1 shRNA only; $p<0.001, F_{(1,100)}=27.05, p<0.001$ for NRLN1 OX only; $p=$ $0.645, F_{(1,100)}=0.21$ for interaction, two-way ANOVA). Moreover, there were prominent qualitative differences in spine morphology between neurons overexpressing NRLN1 in the presence or absence of BAI1 (Fig. 9A), suggesting that BAI1 is more important for NRLN1-induced spinogenesis than our quantitative results would initially suggest. Indeed, synaptic analysis revealed a more dramatic effect of BAI1 loss on NRLN1-induced excitatory synaptogenesis. NRLN1 overexpression increased the density of excitatory synapses in control neurons but failed to increase excitatory synapse density in neurons in which BAI1 was knocked down (Fig. 9E,F), suggesting that BAI1 is critical for NRLN1-induced synaptogenesis. It is possible that, in the absence of BAI1, NRLN1 promotes the formation of spines that lack associated synapses. Together, these results indicate that NRLN1 functionally interacts with BAI1 at synapses to promote spinogenesis/synaptogenesis.

\section{Discussion}

Here, we demonstrate that the A-GPCR BAI1 is necessary in vivo for hippocampal spinogenesis, and we show, for the first time, that it regulates spine and excitatory synapse development via its extracellular NTS and Stachel activation mechanism. Moreover, 
A
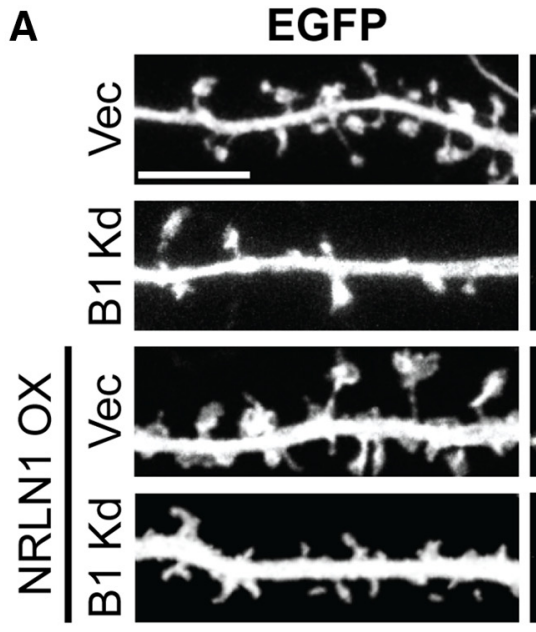

B

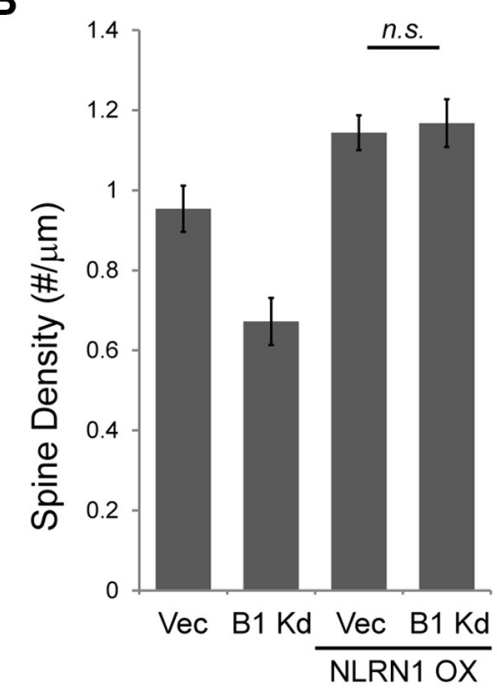

BAI1
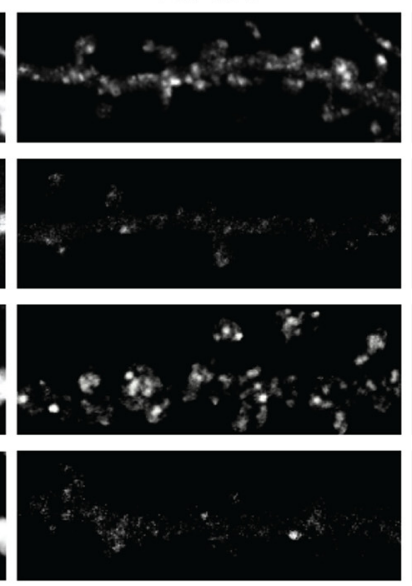

C

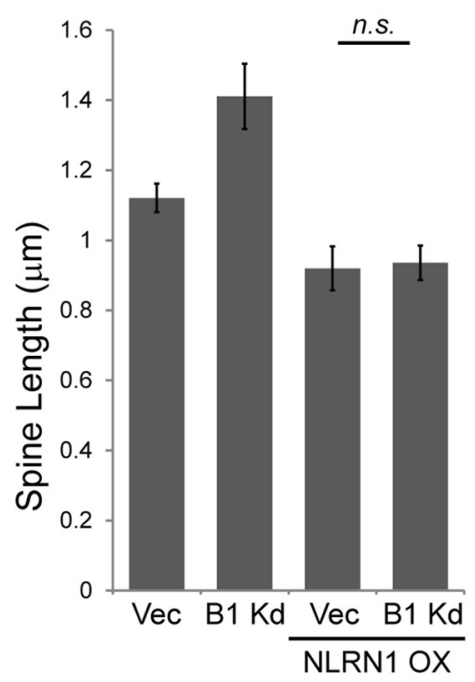

HA
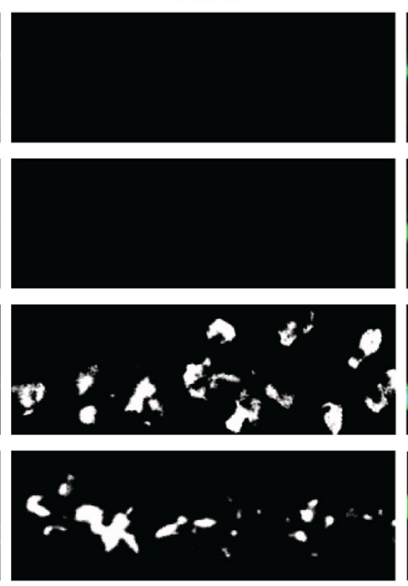

Overlay

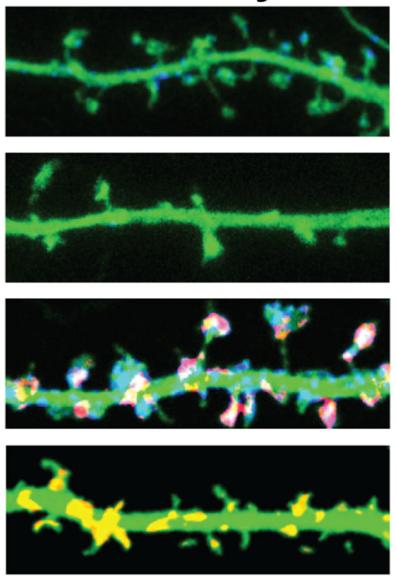

D

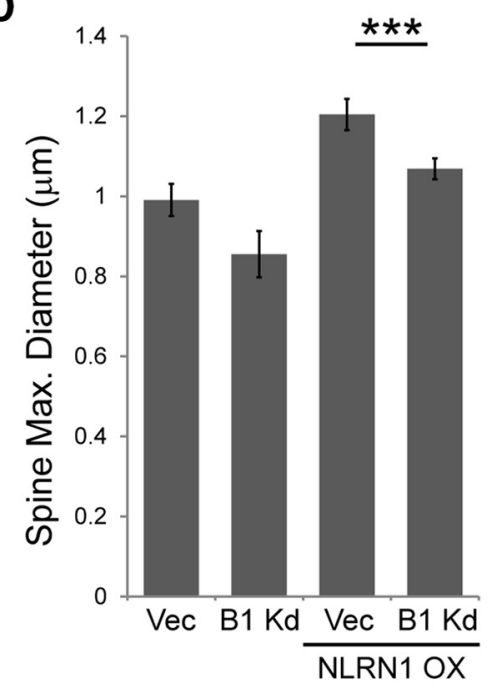

F

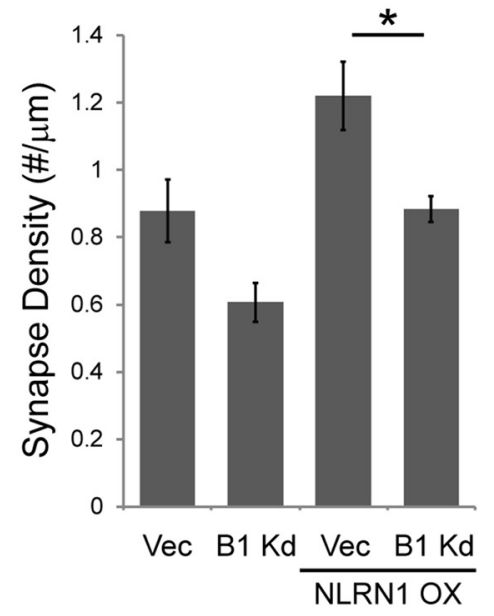

Figure 9. BAI1 is essential for NRLN1-induced spine growth and excitatory synaptogenesis. $A$, Requirement for BAI1 in NRLN1-induced spinogenesis. Rat hippocampal neurons (DIV 6 - 8) were transfected with EGFP and empty vector or HA-tagged NRLN1 (NRLN1 OX) in combination with either pSuper vector (Vec) or shRNA directed against BAl1 (B1 Kd). At 21 DIV, neurons were fixed and stained for BAI1 and HA to evaluate BAI1 Kd and NRLN1 overexpression, respectively. Secondary dendrites on EGFP-expressing neurons were imaged and subjected to spine morphometric analysis ( $N=4 ; n=19-34$ neurons per condition). Scale bar, $5 \mu \mathrm{m}$. B, Quantification of spine density from $(\boldsymbol{A})$ NRLN1 overexpression increased spine density in both vector control and BAl1 Kd (B1 Kd) neurons (WTB1 Kd vs NRLN1 OX B1 Kd, $p<0.001, t=6.14 ; p=0.035, F_{(1,101)}=4.58$ for BAl1 Kd only, $p<0.001, F_{(1,101)}=40.54$ for NRLN1 0X only, and $p=0.012, F_{(1,101)}=6.62$ for interaction, two-way ANOVA). C, Quantification of spine length from $(\boldsymbol{A})$ NRLN1 overexpression decreased spine length in both vector control and BAI1 Kd (B1 Kd) neurons (B1 Kd vs NRLN1 0X B1 Kd, $p<0.001$, $t=-5.46 ; p=0.028, F_{(1,101)}=4.95$ for BAl1 Kd only, $p<0.001, F_{(1,101)}=34.38$ for NRLN1 OX only, and $p=0.053, F_{(1,101)}=3.8$ for interaction, tw0-way ANOVA). $D, 0$ uantification of spine maximum diameter from $\boldsymbol{A}$. NRLN1 overexpression failed to increase spine width to the same extent in BAl1 Kd (B1 Kd) neurons as in vector control neurons. In addition, as shown in $\boldsymbol{A}$, the morphology of spines on NRLN1-overexpressing neurons appeared markedly different in the absence of BAI1 (Vec vs B1 Kd, $p=0.021, t=-2.94$; NRLN1 0X Vec vs (Figure legend continues.) 


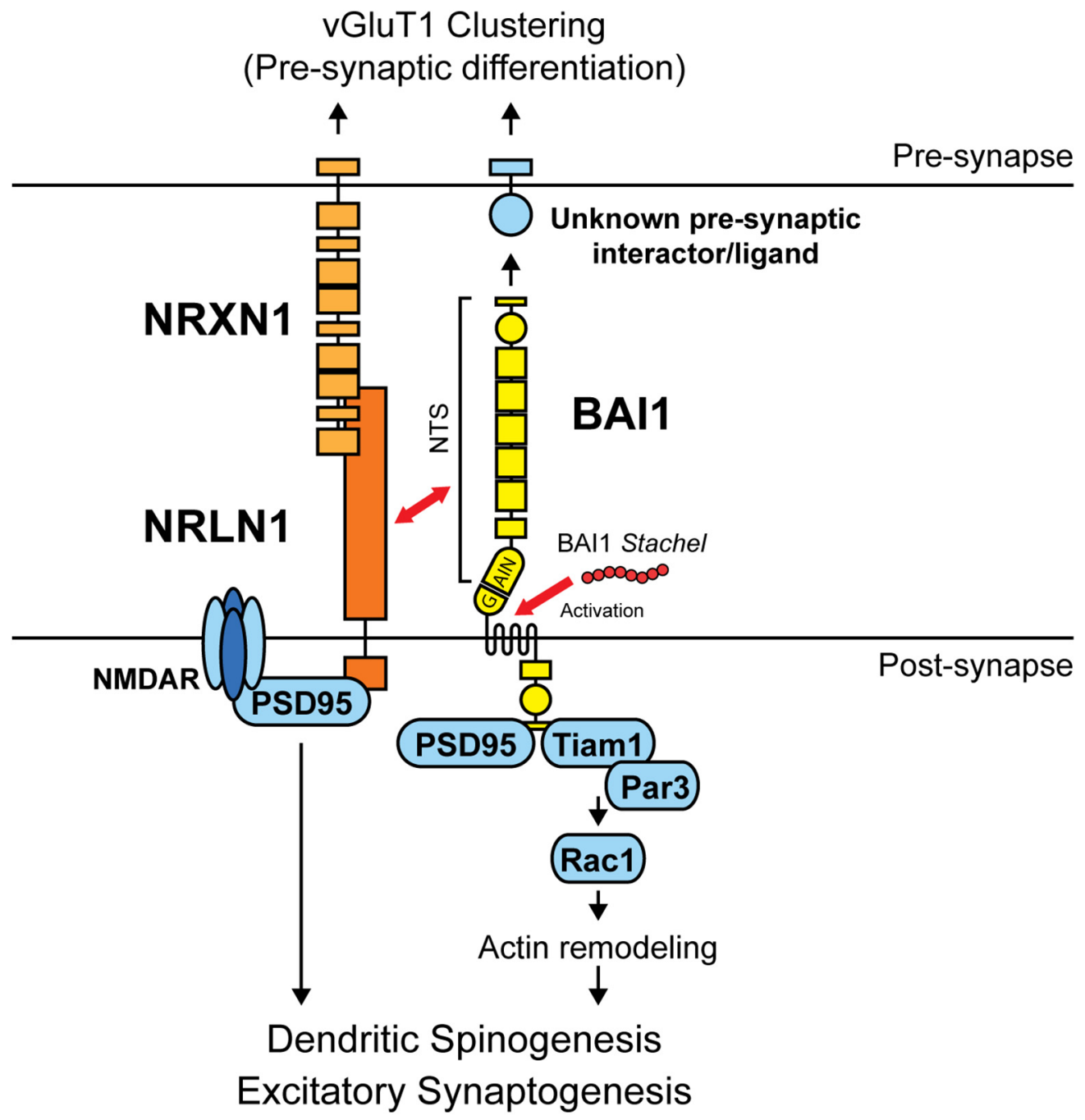

Figure 10. BAl1 promotes spine and synapse development by coordinating bidirectional trans-synaptic signaling. In our model, the postsynaptic A-GPCR BAI1 coordinates bidirectional signaling to promote both spinogenesis and excitatory synaptogenesis, and these functions of BAI1 require its NTS. BAl1 activation by a BAI1 Stachel-derived peptide results in increased postsynaptic Rac1 activity and an enhancement of BAI1's pro-spinogenic/synaptogenic functions. BAI1 likely promotes spine/synapse development by both activating Rac1-mediated actin cytoskeletal remodeling via the Tiam1/Par3 complex and by stabilizing PSD-95 by inhibiting its degradation via MDM2 (data not shown). BAl1 is also capable of reverse trans-synaptic signaling to induce vGluT1 clustering and presynaptic differentiation, although the presynaptic binding partner for BAl1 is currently unknown. Notably, BAl1 appears to regulate spine and synapse development in cooperation with another postsynaptic cell-adhesion molecule NRLN1. NRLN1 facilitates BAl1 localization at dendritic spines, whereas BAl1 is required for NRLN1-induced spine growth and excitatory synaptogenesis. Red arrows indicate interaction/activation. Black arrows indicate signaling direction.

our results reveal that BAI1 is capable of trans-synaptic signaling. In addition to activating Rac1 postsynaptically, which drives actin remodeling essential for spine and synapse growth, BAIl signals to contacting axons, inducing presynaptic protein clustering.

\section{$\leftarrow$}

(Figure legend continued.) $\quad$ NRLN1 OX B1 Kd, $p=0.03, t=-2.80 ; p<0.001, F_{(1,100)}=$ 16.45 for BAl1 Kd only; $p<0.001, F_{(1,100)}=27.05, p<0.001$ for NRLN1 OX only; $p=0.645$, $F_{(1,100)}=0.21$ for interaction, two-way ANOVA). $\boldsymbol{E}$, Requirement for BAl1 in NRLN1-induced excitatory synaptogenesis. Rat hippocampal neurons (DIV 6 - 8) from the same population as in $\boldsymbol{A}$ were fixed and stained at 21 DIV for the presynaptic marker vGluT1 and the postsynaptic marker PSD-95, and overlapping vGluT1/PSD-95 puncta (represented as white signal in the fourth column) were used to quantify excitatory synapse density on transfected cells. Shown are representative secondary dendrites used for quantification $(N=3 ; n=14-19$ neurons per condition). Scale bar, $5 \mu \mathrm{m}$. $\boldsymbol{F}$, Quantification of excitatory synapse density on 21 DIV neurons from $\boldsymbol{E}$. Unlike spine density (but similar to spine maximum diameter), NRLN1-driven excitatory synaptogenesis is compromised by BAl1 Kd (Vec vs B1 Kd, $p=0.040, t=-2.73$; NRLN1 OXVec vs NRLN1 OX B1 Kd, $p=0.047, t=-2.66 ; p<0.001, F_{(1,63)}=14.42$ for BAl1 Kd only, $p<$ $0.001, F_{(1,63)}=18.60$ for NRLN1 OX only, $p=0.836, F_{(1,63)}=0.04$ for interaction, two-way ANOVA; $N=3$ experiments; $n=14-19$ neurons each condition). Data are mean \pm SEM. ${ }^{*} p<$ $0.05,{ }^{* * *} p<0.001$. Not significant $(p>0.05)$.
Our results also indicate that BAI1 regulates excitatory synapse development in cooperation with the postsynaptic cell-adhesion molecule NRLN1. NRLN1 facilitates BAI1 localization at dendritic spines, and BAI1 is required for NRLN1-induced spine growth and excitatory synaptogenesis. Together, these findings provide exciting insights into the molecular mechanisms by which BAI1 promotes dendritic spine and excitatory synapse development, as outlined in our model (Fig. 10).

\section{BAI1 is a critical signaling hub for spine and} synapse development

We have shown that sparse in vivo Kd of BAI1 in both the mouse cortex (Duman et al., 2013) and hippocampus (Fig. 1) leads to decreased spine density and long, narrow immature spines. Sparse BAI1 Kd in dissociated rat hippocampal neurons results in similar spine defects and accompanying excitatory synapse loss. These data differ from those obtained in global BAIl knock-out $(\mathrm{KO})$ mice, where no change in spine density was observed, despite deficits in spine size and synaptic plasticity (Zhu et al., 2015). How can these varying phenotypes be resolved? Because 
spine densities are decreased in the brains of mice with sparse BAI1 Kd but not global BAI1 loss, relative levels of BAIl between neighboring neurons may regulate excitatory synapse number. Kwon et al. (2012) observed a similar effect for NRLN1 (which interacts with BAI1): total KO of NRLN1 and closely related NRLN2/3 caused defects in synapse maturation and plasticity but had little effect on spine density, whereas sparse NRLN1 KO resulted in decreased excitatory synapse density in NRLN1deficient neurons. This result suggests that some synaptogenic factors exert their effects through differences in their relative (rather than absolute) expression levels between neighboring neurons and potentially even between individual synapses. Thus, the spinogenic and synaptogenic functions of BAIl are likely to be highly context-dependent, as implied by differences between our results and results from BAIl KO mice (Zhu et al., 2015). An intriguing possibility is that receptors, such as BAI1 and NRLN1, regulate synapse development by competing for synaptogenic inputs that refine and reinforce more robust synaptic structures.

BAI1 promotes spine and synapse development via multiple signaling pathways illustrated in Figure 10. Previously, we showed that BAI1 recruits and/or anchors the polarity complex Tiam1/Par3 to postsynaptic sites, resulting in the local activation of Rac1, which controls actin cytoskeletal remodeling in spines (Duman et al., 2013). BAIl also stabilizes the postsynaptic scaffold PSD-95 by binding to and inhibiting the E3 ubiquitin ligase MDM2, which targets PSD-95 for degradation (Zhu et al., 2015). Given BAI1's structure and role in ligand-stimulated phagocytosis (Park et al., 2007), it is logical to assume that an external signal regulates these BAI1-mediated synaptic processes, but this remains unproven. Consistent with this idea, closely related A-GPCR BAI3 uses a ligand-dependent mechanism in the cerebellum to regulate the formation and refinement of Purkinje cellclimbing fiber excitatory synapses (Kakegawa et al., 2015; Sigoillot et al., 2015). Specifically, secreted complement C1q-like factor C1ql1, expressed by inferior olivary neurons, interacts with BAI3 on Purkinje cell spines and controls the stereotyped pattern of synaptic connectivity formed between climbing fiber excitatory afferents and Purkinje cells (Kakegawa et al., 2015; Sigoillot et al., 2015). Our finding that the extracellular NTS of BAI1 is necessary for spinogenesis/synaptogenesis is significant because it supports the hypothesis that BAI1 regulates these processes in response to an external synaptogenic signal. Moreover, our results with the BAI1-Stachel peptide provide additional evidence that BAIl functions as a receptor to promote Rac1-dependent synaptogenesis in response to an external signal. Like BAI3, BAI1 may form and maintain specific synapses that contain ligandactivated BAI1. The nature of this synaptogenic signal remains unknown but could be complex, as BAIl has multiple potential ligand-binding sites (Fig. 2) (Duman et al., 2016) and could respond to several different ligands and even integrate these distinct signals.

\section{Stachel-mediated BAI1 activation promotes spinogenesis and excitatory synaptogenesis}

The Stachel activation mechanism has been a watershed discovery in A-GPCR signaling for several reasons. First, it reveals a novel signaling paradigm common to A-GPCRs, many of which are orphan receptors with no known function. Second, it provides a simple method using Stachel sequence-derived peptides to activate these A-GPCRs to explore their physiological and therapeutic roles and functional implications without needing to identify their native ligands. We used the BA1-Stachel peptide as a tool to activate BAI1 in the absence of a BAI1 ligand, and it enhanced both Racl activation and spinogenesis/synaptogenesis in developing neurons in a BAI1-dependent manner (Fig. 4). These responses were relatively rapid, occurring within an hour of BA1Stachel peptide stimulation, consistent with timescales of local cytoskeletal remodeling. It is not clear whether BAI1-Stachel activates BAI1 signaling via the canonical mechanism proposed by Liebscher et al. (2014). In this model, A-GPCRs exist as heterodimers due to autoproteolytic cleavage of their GAIN domain, after which their $\mathrm{N}$ - and $\mathrm{C}$-terminal segments remain noncovalently associated. Ligand binding to the NTS promotes heterodimer dissociation, exposing the Stachel sequence in the C-terminal segment, which activates heterotrimeric G-protein signaling via the GPCR domain. Many A-GPCRs have been shown to function in this manner (Liebscher et al., 2014; Demberg et al., 2015; Petersen et al., 2015; Wilde et al., 2016), but there are notable differences between canonical and BAI1-Stachel signaling. First, while BAIl can autoproteolyze at the GAIN domain (Kaur et al., 2005), our evidence indicates that it does not do so in neurons. WBs of neuronal lysates show that BAI1 is predominantly full-length or cleaved between amino acids 321-329 (Fig. 2) (Cork et al., 2012). Second, canonical Stachel signaling is GPCR-dependent (Liebscher et al., 2014). BAIl is capable of coupling to $\mathrm{G} \alpha_{12 / 13}$ and promoting RhoA activation (Stephenson et al., 2013), but no evidence to date links this signaling pathway to BAI1-mediated spine/synapse development. Moreover, the canonical Stachel model predicts that NTS removal should expose the Stachel sequence in BAIl, leading to constitutive receptor activation; this prediction has held for several A-GPCRs, including BAI2 (Liebscher et al., 2014; Demberg et al., 2015; Petersen et al., 2015; Wilde et al., 2016; Purcell et al., 2017). However, we demonstrate that removal of BAIl's NTS $(\mathrm{B} 1 \Delta \mathrm{N})$ renders it incapable of rescuing defects in spine/synapse development caused by BAI1 Kd (Fig. 2), implying that this mutant is inhibited rather than constitutively activated. Thus, we propose that BAI1-Stachel signals in a noncanonical manner (Fig. 10). In support of this, Kishore et al. (2016) reported that, in heterologous cells, BAI1 displays increased GPCR signaling activity in the absence of the Stachel sequence. Accumulating evidence indicates that other A-GPCRs may also signal through noncanonical mechanisms. For instance, Salzman et al. (2017) showed that synthetic monobody ligands for GPR56 could still modulate GPCR signaling of a GPR56 mutant defective in autoproteolysis and thus Stachel peptide exposure. Because removal of BAIl's NTS does not replicate activation of BAI1 via BAI1 Stachel, a more likely model for BAI1 Stachel signaling may be unrelated to proteolysis. BAI1's ligand may be triggering conformational changes in BAI1 that align its Stachel sequence into the correct position to induce downstream signaling in a manner that $\mathrm{B} 1 \Delta \mathrm{N}$ cannot replicate. Thus, our finding of BAI1-Stachel signaling in excitatory synapse development raises many new questions and potential avenues of discovery. For instance, what is the mechanism by which Stachel activates BAIl and induces rapid Racl activation and spine/synapse development? Is the Stachel-BAI1 pathway always engaged throughout development or is it regulated temporally and are the downstream effects always the same? Our observation of a critical period for Stachel activity in spinogenesis and Racl activation (Figs. 4, 5) indicates that BAI1-Stachel signaling is regulated temporally. As a final note, recent reports have demonstrated that some Stachel sequences have nonspecific activity on multiple A-GPCRs (Demberg et al., 2017). Stachel sequences for BAI1/2/3 are similar, so it is possible that BAI1-Stachel activates BAI2/3. However, BAI1 Kd ablates the effects of BAI1-Stachel (Figs. 4, 5), 
so it is reasonable to posit that BAI1 activation by BAI1-Stachel accounts for the effects that we report here.

\section{BAI1 induces presynaptic differentiation}

To our knowledge, BAIl is one of the first A-GPCRs to be identified as a trans-synaptic inducer of presynaptic development (along with Latrophillin-2) (Anderson et al., 2017). Not only does BAI1 mediate spine/synapse development through Rac1mediated cytoskeletal changes and PSD-95 stabilization, but it also induces presynaptic protein clustering (Fig. 10). Thus, our observation that BAI1 Kd decreases excitatory synapse density (Figs. 2,3) (Duman et al., 2013) may be caused by defects in both presynaptic and postsynaptic development. Although BAI1 appears less potent at inducing vGluT1 clustering than NLRN1 in our mixed-culture assays (Fig. 6), we cannot be sure that BAI1 and NRLN1 were expressed at the same level as they were detected with different antibodies. Nevertheless, it is reasonable to posit that the presynaptic clustering functions of these two proteins are not exactly the same. Unlike the well-established NRLN1-NRXN1 pairing (Scheiffele et al., 2000), BAI1 has no known presynaptic partner to explain its mechanism. BAIl fails to bind either NRXN1 or NRLN1 in trans, indicating that they are unlikely binding partners for BAIl across the synapse (Fig. 10). However, our discovery of a functional postsynaptic BAI1NRLN1 interaction suggests that BAI1 may work in cooperation with NRLN1 and other synaptic partners in promoting presynaptic differentiation.

BAI1 and NRLN1 functionally interact at excitatory synapses As mentioned, NRLN1 is an important regulator of excitatory synapse development and plasticity, and both it and its family members NRLN3/4 are implicated in human diseases, including ASD and intellectual disability (Jamain et al., 2003; Baudouin et al., 2012; Millson et al., 2012; Baudouin, 2014; Cao and Tabuchi, 2017; Nakanishi et al., 2017). Notably, we show here that NRLN1 is a partner for BAI1 at excitatory synapses. NRLN1 robustly interacts with BAIl and colocalizes with it at postsynaptic termini. Intriguingly, NRLN1 and BAI1 are functionally dependent on one another. Previous work demonstrated that in vivo overexpression of NRLN1 in newborn granule cells increases the density of dendritic spines and functional excitatory synapses (Schnell et al., 2012). Moreover, expression of NRLN1 under the control of the Thy-1 promoter increases excitatory synapse markers, spine density, and spine head and neck sizes (Dahlhaus et al., 2010). Our results confirm these observations (Fig. 9) and suggest that BAI1 is required for NRLN1's ability to increase spine head diameter and excitatory synapse density (Figs. 9, 10).

The precise mechanisms by which BAIl and NRLN1 cooperate at synapses remain elusive. We show that the BAI1 NTS is sufficient to bind to NRLN1 (Fig. 7C,D), but the specific domains that mediate the BAI1-NRLN1 interaction are unclear. In terms of their functional interaction, NRLN1 may play a role in targeting and/or stabilizing BAI1 at synapses because synaptic BAI1 levels decreased upon NRLN1 Kd (Fig. 8F, G). On the other hand, BAI1 may contribute to NRLN1-mediated excitatory synaptogenesis by inducing local Racl activation and/or stabilizing the key synaptic scaffolding protein PSD-95, a critical downstream partner for NRLN1 (Fig. 10) (Irie et al., 1997; Bolliger et al., 2001; Prange et al., 2004; Futai et al., 2007; Barrow et al., 2009; Schapitz et al., 2010; Zhu et al., 2015). As NRLN1 and PSD-95 both positively regulate NMDAR synaptic abundance and signaling (Budreck et al., 2013; Chen et al., 2015; Won et al., 2016; Zhang and Südhof, 2016), it is also possible that BAIl cooperates with these proteins in regulating NMDAR function at synapses (Zhu et al., 2015). In the future, it will be interesting to investigate whether the BAI1-NRLN1 interaction contributes to synaptic plasticity as well as synaptogenesis.

Results presented here expand our knowledge of BAI1 as a promoter of spinogenesis and synaptogenesis. Excitingly, we demonstrate, for the first time, that (1) BAIl functions via a noncanonical Stachel-dependent mechanism to activate Rac1mediated spine and synapse development, (2) BAI1 signals transsynaptically to induce presynaptic terminal differentiation, and (3) BAI1 interacts and cooperates with NRLN1 to promote spinogenesis and synaptogenesis. These functions suggest that BAI1 is, or forms part of, an important synaptogenic signaling hub whose composition, function, and mechanism(s) of action are still largely unknown. Solving this puzzle will greatly impact our knowledge of synapse development and function and could also be instrumental in the development of new therapeutic interventions for treating neuropsychiatric diseases involving synapse pathology.

\section{References}

Aiga M, Levinson JN, Bamji SX (2011) N-cadherin and neuroligins cooperate to regulate synapse formation in hippocampal cultures. J Biol Chem 286:851-858. CrossRef Medline

Anderson GR, Maxeiner S, Sando R, Tsetsenis T, Malenka RC, Südhof TC (2017) Postsynaptic adhesion GPCR latrophilin-2 mediates target recognition in entorhinal-hippocampal synapse assembly. J Cell Biol 216:38313846. CrossRef Medline

Arac D, Boucard AA, Bolliger MF, Nguyen J, Soltis SM, Südhof TC, Brunger AT (2012) A novel evolutionarily conserved domain of cell-adhesion GPCRs mediates autoproteolysis. EMBO J 31:1364-1378. CrossRef Medline

Barrow SL, Constable JR, Clark E, El-Sabeawy F, McAllister AK, Washbourne P (2009) Neuroligin 1: a cell adhesion molecule that recruits PSD-95 and NMDA receptors by distinct mechanisms during synaptogenesis. Neural Dev 4:17. CrossRef Medline

Baudouin SJ (2014) Heterogeneity and convergence: the synaptic pathophysiology of autism. Eur J Neurosci 39:1107-1113. CrossRef Medline

Baudouin SJ, Gaudias J, Gerharz S, Hatstatt L, Zhou K, Punnakkal P, Tanaka KF, Spooren W, Hen R, De Zeeuw CI, Vogt K, Scheiffele P (2012) Shared synaptic pathophysiology in syndromic and nonsyndromic rodent models of autism. Science 338:128-132. CrossRef Medline

Biederer T, Scheiffele P (2007) Mixed-culture assays for analyzing neuronal synapse formation. Nat Protoc 2:670-676. CrossRef Medline

Bolliger MF, Frei K, Winterhalter KH, Gloor SM (2001) Identification of a novel neuroligin in humans which binds to PSD-95 and has a widespread expression. Biochem J 356:581-588. CrossRef Medline

Budreck EC, Kwon OB, Jung JH, Baudouin S, Thommen A, Kim HS, Fukazawa Y, Harada H, Tabuchi K, Shigemoto R, Scheiffele P, Kim JH (2013) Neuroligin-1 controls synaptic abundance of NMDA-type glutamate receptors through extracellular coupling. Proc Natl Acad Sci U S A 110: 725-730. CrossRef Medline

Cao X, Tabuchi K (2017) Functions of synapse adhesion molecules neurexin/neuroligins and neurodevelopmental disorders. Neurosci Res 116: 3-9. CrossRef Medline

Chahrour M, Jung SY, Shaw C, Zhou X, Wong ST, Qin J, Zoghbi HY (2008) Mecp2, a key contributor to neurological disease, activates and represses transcription. Science 320:1224-1229. CrossRef Medline

Chanda S, Hale WD, Zhang B, Wernig M, Südhof TC (2017) Unique versus redundant functions of neuroligin genes in shaping excitatory and inhibitory synapse properties. J Neurosci 37:6816-6836. CrossRef Medline

Chen X, Levy JM, Hou A, Winters C, Azzam R, Sousa AA, Leapman RD, Nicoll RA, Reese TS (2015) PSD-95 family Maguks are essential for anchoring AMPA and NMDA receptor complexes at the postsynaptic density. Proc Natl Acad Sci U S A 112:E6983-E6992. CrossRef Medline

Chih B, Engelman H, Scheiffele P (2005) Control of excitatory and inhibitory synapse formation by neuroligins. Science 307:1324-1328. CrossRef Medline

Cork SM, Kaur B, Devi NS, Cooper L, Saltz JH, Sandberg EM, Kaluz S, Van 
Meir EG (2012) A proprotein convertase/MMP-14 proteolytic cascade releases a novel $40 \mathrm{kDa}$ vasculostatin from tumor suppressor BAIl. Oncogene 31:5144-5152. CrossRef Medline

Cork SM, Van Meir EG (2011) Emerging roles for the BAI1 protein family in the regulation of phagocytosis, synaptogenesis, neurovasculature, and tumor development. J Mol Med (Berl) 89:743-752. CrossRef Medline

Craig AM, Kang Y (2007) Neurexin-neuroligin signaling in synapse development. Curr Opin Neurobiol 17:43-52. CrossRef Medline

Dahlhaus R, El-Husseini A (2010) Altered neuroligin expression is involved in social deficits in a mouse model of the fragile $\mathrm{X}$ syndrome. Behav Brain Res 208:96-105. CrossRef Medline

Dahlhaus R, Hines RM, Eadie BD, Kannangara TS, Hines DJ, Brown CE, Christie BR, El-Husseini A (2010) Overexpression of the cell adhesion protein neuroligin-1 induces learning deficits and impairs synaptic plasticity by altering the ratio of excitation to inhibition in the hippocampus. Hippocampus 20:305-322. CrossRef Medline

Demberg LM, Rothemund S, Schöneberg T, Liebscher I (2015) Identification of the tethered peptide agonist of the adhesion $\mathrm{G}$ protein-coupled receptor GPR64/ADGRG2. Biochem Biophys Res Commun 464:743747. CrossRef Medline

Demberg LM, Winkler J, Wilde C, Simon KU, Schön J, Rothemund S, Schöneberg T, Prömel S, Liebscher I (2017) Activation of adhesion G protein-coupled receptors: agonist specificity of Stachel sequence-derived peptides. J Biol Chem 292:4383-4394. CrossRef Medline

Duman JG, Tzeng CP, Tu YK, Munjal T, Schwechter B, Ho TS, Tolias KF (2013) The adhesion-GPCR BAIl regulates synaptogenesis by controlling the recruitment of the Par3/Tiam1 polarity complex to synaptic sites. J Neurosci 33:6964-6978. CrossRef Medline

Duman JG, Tu YK, Tolias KF (2016) Emerging roles of BAI adhesionGPCRs in synapse development and plasticity. Neural Plast 2016: 8301737. CrossRef Medline

Feige JN, Sage D, Wahli W, Desvergne B, Gelman L (2005) PixFRET, an ImageJ plug-in for FRET calculation that can accommodate variations in spectral bleed-throughs. Microsc Res Tech 68:51-58. CrossRef Medline

Futai K, Kim MJ, Hashikawa T, Scheiffele P, Sheng M, Hayashi Y (2007) Retrograde modulation of presynaptic release probability through signaling mediated by PSD-95-neuroligin. Nat Neurosci 10:186-195. CrossRef Medline

Gerrow K, Romorini S, Nabi SM, Colicos MA, Sala C, El-Husseini A (2006) A preformed complex of postsynaptic proteins is involved in excitatory synapse development. Neuron 49:547-562. CrossRef Medline

Gibson DG, Young L, Chuang RY, Venter JC, Hutchison CA 3rd, Smith HO (2009) Enzymatic assembly of DNA molecules up to several hundred kilobases. Nat Methods 6:343-345. CrossRef Medline

Govek EE, Newey SE, Van Aelst L (2005) The role of the rho GTPases in neuronal development. Genes Dev 19:1-49. CrossRef Medline

Hedstrom KL, Xu X, Ogawa Y, Frischknecht R, Seidenbecher CI, Shrager P, Rasband MN (2007) Neurofascin assembles a specialized extracellular matrix at the axon initial segment. J Cell Biol 178:875-886. CrossRef Medline

Hu X, Luo JH, Xu J (2015) The interplay between synaptic activity and neuroligin function in the CNS. Biomed Res Int 2015:498957. CrossRef Medline

Irie M, Hata $\mathrm{Y}$, Takeuchi M, Ichtchenko K, Toyoda A, Hirao K, Takai Y, Rosahl TW, Südhof TC (1997) Binding of neuroligins to psd-95. Science 277:1511-1515. CrossRef Medline

Jamain S, Quach H, Betancur C, Råstam M, Colineaux C, Gillberg IC, Soderstrom H, Giros B, Leboyer M, Gillberg C, Bourgeron T (2003) Mutations of the X-linked genes encoding neuroligins NLGN3 and NLGN4 are associated with autism. Nat Genet 34:27-29. CrossRef Medline

Kakegawa W, Mitakidis N, Miura E, Abe M, Matsuda K, Takeo YH, Kohda K, Motohashi J, Takahashi A, Nagao S, Muramatsu S, Watanabe M, Sakimura K, Aricescu AR, Yuzaki M (2015) Anterograde Clql1 signaling is required in order to determine and maintain a single-winner climbing fiber in the mouse cerebellum. Neuron 85:316-329. CrossRef Medline

Kaur B, Brat DJ, Devi NS, Van Meir EG (2005) Vasculostatin, a proteolytic fragment of brain angiogenesis inhibitor 1, is an antiangiogenic and antitumorigenic factor. Oncogene 24:3632-3642. CrossRef Medline

Kishore A, Purcell RH, Nassiri-Toosi Z, Hall RA (2016) Stalk-dependent and stalk-independent signaling by the adhesion $\mathrm{G}$ protein-coupled receptors GPR56 (ADGRG1) and BAI1 (ADGRB1). J Biol Chem 291:33853394. CrossRef Medline
Koh JT, Lee ZH, Ahn KY, Kim JK, Bae CS, Kim HH, Kee HJ, Kim KK (2001) Characterization of mouse brain-specific angiogenesis inhibitor 1 (BAI1) and phytanoyl-CoA alpha-hydroxylase-associated protein 1, a novel BAI1-binding protein. Brain Res Mol Brain Res 87:223-237. CrossRef Medline

Komatsu N, Aoki K, Yamada M, Yukinaga H, Fujita Y, Kamioka Y, Matsuda M (2011) Development of an optimized backbone of fret biosensors for kinases and GTPases. Mol Biol Cell 22:4647-4656. CrossRef Medline

Kulkarni VA, Firestein BL (2012) The dendritic tree and brain disorders. Mol Cell Neurosci 50:10-20. CrossRef Medline

Kwon HB, Kozorovitskiy Y, Oh WJ, Peixoto RT, Akhtar N, Saulnier JL, Gu C, Sabatini BL (2012) Neuroligin-1-dependent competition regulates cortical synaptogenesis and synapse number. Nat Neurosci 15:1667-1674. CrossRef Medline

Liebscher I, Schön J, Petersen SC, Fischer L, Auerbach N, Demberg LM, Mogha A, Cöster M, Simon KU, Rothemund S, Monk KR, Schöneberg T (2014) A tethered agonist within the ectodomain activates the adhesion G protein-coupled receptors GPR126 and GPR133. Cell Rep 9:20182026. CrossRef Medline

Linhoff MW, Laurén J, Cassidy RM, Dobie FA, Takahashi H, Nygaard HB, Airaksinen MS, Strittmatter SM, Craig AM (2009) An unbiased expression screen for synaptogenic proteins identifies the LRRTM protein family as synaptic organizers. Neuron 61:734-749. CrossRef Medline

Maro GS, Gao S, Olechwier AM, Hung WL, Liu M, Özkan E, Zhen M, Shen K (2015) Madd-4/punctin and neurexin organize C. elegans gabaergic postsynapses through neuroligin. Neuron 86:1420-1432. CrossRef Medline

Michaelson JJ, Shi Y, Gujral M, Zheng H, Malhotra D, Jin X, Jian M, Liu G, Greer D, Bhandari A, Wu W, Corominas R, Peoples A, Koren A, Gore A, Kang S, Lin GN, Estabillo J, Gadomski T, Singh B, et al. (2012) Wholegenome sequencing in autism identifies hot spots for de novo germline mutation. Cell 151:1431-1442. CrossRef Medline

Millson A, Lagrave D, Willis MJ, Rowe LR, Lyon E, South ST (2012) Chromosomal loss of 3q26.3-3q26.32, involving a partial neuroligin 1 deletion, identified by genomic microarray in a child with microcephaly, seizure disorder, and severe intellectual disability. Am J Med Genet A 158A:159-165. CrossRef Medline

Nakanishi M, Nomura J, Ji X, Tamada K, Arai T, Takahashi E, Bucan M, Takumi T (2017) Functional significance of rare neuroligin 1 variants found in autism. PLoS Genet 13: e1006940. CrossRef Medline

Park D, Tosello-Trampont AC, Elliott MR, Lu M, Haney LB, Ma Z, Klibanov AL, Mandell JW, Ravichandran KS (2007) BAI1 is an engulfment receptor for apoptotic cells upstream of the ELMO/Dock180/Rac module. Nature 450:430-434. CrossRef Medline

Petersen SC, Luo R, Liebscher I, Giera S, Jeong SJ, Mogha A, Ghidinelli M, Feltri ML, Schöneberg T, Piao X, Monk KR (2015) The adhesion GPCR GPR126 has distinct, domain-dependent functions in Schwann cell development mediated by interaction with laminin-211. Neuron 85:755769. CrossRef Medline

Prange O, Wong TP, Gerrow K, Wang YT, El-Husseini A (2004) A balance between excitatory and inhibitory synapses is controlled by PSD-95 and neuroligin. Proc Natl Acad Sci U S A 101:13915-13920. CrossRef Medline

Purcell RH, Toro C, Gahl WA, Hall RA (2017) A disease-associated mutation in the adhesion GPCR BAI2 (ADGRB2) increases receptor signaling activity. Hum Mutat 38:1751-1760. CrossRef Medline

Salzman GS, Zhang S, Gupta A, Koide A, Koide S, Arac D (2017) Stachelindependent modulation of GPR56/ADGRG1 signaling by synthetic ligands directed to its extracellular region. Proc Natl Acad Sci U S A 114: 10095-10100. CrossRef Medline

Schapitz IU, Behrend B, Pechmann Y, Lappe-Siefke C, Kneussel SJ, Wallace KE, Stempel AV, Buck F, Grant SG, Schweizer M, Schmitz D, Schwarz JR, Holzbaur EL, Kneussel M (2010) Neuroligin 1 is dynamically exchanged at postsynaptic sites. J Neurosci 30:12733-12744. CrossRef Medline

Scheiffele P, Fan J, Choih J, Fetter R, Serafini T (2000) Neuroligin expressed in nonneuronal cells triggers presynaptic development in contacting axons. Cell 101:657-669. CrossRef Medline

Schnell E, Bensen AL, Washburn EK, Westbrook GL (2012) Neuroligin-1 overexpression in newborn granule cells in vivo. PLoS One 7:e48045. CrossRef Medline

Sigoillot SM, Iyer K, Binda F, Gonzalez-Calvo I, Talleur M, Vodjdani G, Isope P, Selimi F (2015) The secreted protein C1ql1 and its receptor BAI3 
control the synaptic connectivity of excitatory inputs converging on cerebellar Purkinje cells. Cell Rep 10:820-832. CrossRef Medline

Song JY, Ichtchenko K, Südhof TC, Brose N (1999) Neuroligin 1 is a postsynaptic cell-adhesion molecule of excitatory synapses. Proc Natl Acad Sci U S A 96:1100-1105. CrossRef Medline

Stephenson JR, Paavola KJ, Schaefer SA, Kaur B, Van Meir EG, Hall RA (2013) Brain-specific angiogenesis inhibitor-1 signaling, regulation, and enrichment in the postsynaptic density. J Biol Chem 288:22248-22256. CrossRef Medline

Stoveken HM, Hajduczok AG, Xu L, Tall GG (2015) Adhesion G proteincoupled receptors are activated by exposure of a cryptic tethered agonist. Proc Natl Acad Sci U S A 112:6194-6199. CrossRef Medline

Tada T, Sheng M (2006) Molecular mechanisms of dendritic spine morphogenesis. Curr Opin Neurobiol 16:95-101. CrossRef Medline

Tolias KF, Bikoff JB, Burette A, Paradis S, Harrar D, Tavazoie S, Weinberg RJ, Greenberg ME (2005) The Rac1-Gef Tiam1 couples the NMDA receptor to the activity-dependent development of dendritic arbors and spines. Neuron 45:525-538. CrossRef Medline

Wilde C, Fischer L, Lede V, Kirchberger J, Rothemund S, Schöneberg T, Liebscher I (2016) The constitutive activity of the adhesion GPCR
GPR114/ADGRG5 is mediated by its tethered agonist. FASEB J 30:666673. CrossRef Medline

Won S, Incontro S, Nicoll RA, Roche KW (2016) PSD-95 stabilizes NMDA receptors by inducing the degradation of STEP61. Proc Natl Acad Sci U S A 113:E4736-E4744. CrossRef Medline

Woo J, Kwon SK, Choi S, Kim S, Lee JR, Dunah AW, Sheng M, Kim E (2009) Trans-synaptic adhesion between NGL-3 and LAR regulates the formation of excitatory synapses. Nat Neurosci 12:428-437. CrossRef Medline

Xu J, Xiao N, Xia J (2010) Thrombospondin 1 accelerates synaptogenesis in hippocampal neurons through neuroligin 1. Nat Neurosci 13:22-24. CrossRef Medline

Zhang B, Südhof TC (2016) Neuroligins are selectively essential for NMDAR signaling in cerebellar stellate interneurons. J Neurosci 36: 9070-9083. CrossRef Medline

Zhu D, Li C, Swanson AM, Villalba RM, Guo J, Zhang Z, Matheny S, Murakami T, Stephenson JR, Daniel S, Fukata M, Hall RA, Olson JJ, Neigh GN, Smith Y, Rainnie DG, Van Meir EG (2015) BAI1 regulates spatial learning and synaptic plasticity in the hippocampus. J Clin Invest 125: 1497-1508. CrossRef Medline 